\title{
Using pulse testing for leakage detection in carbon storage reservoirs: A field demonstration
}

\author{
Alexander Y. Sun ${ }^{\mathrm{a}, *}$, Jiemin Lu ${ }^{\mathrm{a}}$, Barry M. Freifeld ${ }^{\mathrm{b}}$, Susan D. Hovorka ${ }^{\mathrm{a}}$, \\ Akand Islam ${ }^{\mathrm{a}}$ \\ ${ }^{a}$ Bureau of Economic Geology, Jackson School of Geosciences, University of Texas at \\ Austin, Austin, TX \\ ${ }^{b}$ Earth Sciences Division, Lawrence Berkeley National Laboratory, Berkeley, CA
}

\begin{abstract}
Monitoring techniques capable of deep subsurface detection are desirable for early warning and leakage pathway identification in geologic carbon storage formations. This work demonstrates the feasibility of a pulse-testing-based leakage detection procedure, in which the storage reservoir is stimulated using periodic injection or pulsing patterns and the acquired pressure perturbation signals are analyzed in the frequency domain to detect potential deviations in the reservoir's frequency domain response. Unlike the traditional well testing and associated time domain analyses, pulse testing aims to minimize the interference of reservoir operations and other ambient noise by selecting appropriate pulsing frequencies such that reservoir responses to coded injection patterns can be uniquely determined in frequency domain. Field demonstration of this pulse-testing leakage detection technique was carried out at a $\mathrm{CO}_{2}$ enhanced oil recovery site - the Cranfield site located in Mississippi, USA, which has long been used as a carbon storage research site. During the demonstration, two sets of pulsing experiments (baseline and leak tests) were performed using 90-min and 150-min pulsing periods to demonstrate feasibility of time-lapse leakage
\end{abstract}

\footnotetext{
*Corresponding author, University Station, Box X, Austin, TX 78713

Email address: alex.sun@beg.utexas.edu (Alexander Y. Sun)
}

Preprint submitted to International Journal of Greenhouse Gases ControlDecember 19, 2015

(C) 2016. This manuscript version is made available under the Elsevier user license http://www.elsevier.com/open-access/userlicense/1.0/ 
detection. For leak tests, an artificial leakage source was created through ratecontrolled venting of $\mathrm{CO}_{2}$ from one of the monitoring wells because of the lack of known leakage pathways at the site. Our results show that leakage events caused a significant deviation in the amplitude of the frequency response function, indicating that pulse testing may be deployed as a cost-effective active monitoring technique, with a strong potential for site-wide automated monitoring.

Keywords: Leakage detection, Geological carbon sequestration, Pulse testing, Frequency domain analysis

\section{1. Introduction}

2 Carbon capture and storage (CCS) is being pursued as a large-scale miti3 gation option for making dramatic reductions in greenhouse gas emissions from 4 power plants and other industrial sources. A recent report by the Interna-

5 tional Energy Agency points out that CCS is the "only technology available 6 today that has the potential to protect the climate while preserving the value 7 of fossil fuel reserves and existing infrastructure" [18]. For geologic storage, 8 supercritical $\mathrm{CO}_{2}$ is injected into deep geologic formations that are typically 9 located 1-3 km below surface (e.g., depleted oil and gas reservoirs, unminable 10 coal seams, or saline aquifers). Potential leakage through abandoned wells and 11 geologic faults represent the greatest risk to geologic carbon storage projects. 12 To ensure containment efficiency and public safety, the fate and transport of 13 injected $\mathrm{CO}_{2}$ plume must be closely monitored during the life cycle of a geo14 logical sequestration project. Over the last decade, a wide array of monitoring 15 methods have been developed and demonstrated for leakage detection, includ16 ing pressure monitoring, soil gas monitoring, groundwater sampling, geophysical 17 surveys, vegetation stress, eddy covariance, and remote sensing [26, 42]. Leak18 age pathways tend to be more diffused and the leak signals more attenuated as 19 the distance from the source increases. Thus, monitoring methods/instruments 
capable of deep subsurface detection are more desirable for early warning and leakage pathway identification. Common methods suitable for deep subsurface monitoring can be roughly classified into surface-based and downhole technologies. The former mainly includes time-lapse seismic surveys, while the latter includes wellbore sensors and tools such as downhole pressure and temperature gauges, fluid samplers, microseismic sensors, and distributed optical sensing cables.

Pressure sensing is one of the most studied and, arguably, most well established leakage detection methods for deep subsurface monitoring. A large number of analytical and numerical modeling works have been performed to quantify pressure anomalies resulting from focused leakage (e.g., from faults and abandoned wells) and diffusive leakage (e.g., from leaky caprocks) [e.g., $32,8,37,40,23,10,13,6]$. Major advantages of pressure sensing over other deep subsurface detection technologies include its (i) early detection potential; (ii) cost effectiveness; (iii) suitability for continuous, automated, longterm deployment; and (iv) suitability for optimal sensing or targeted monitoring $[21,38,19,17]$. Concerns over pressure sensing include its lack of sensitivity to "small" leaks and its proneness to noise interference, especially when deployed for monitoring $\mathrm{CO}_{2}$ enhanced oil recovery $\left(\mathrm{CO}_{2}\right.$-EOR) reservoirs. Notwithstanding the large number of theoretical studies, relatively few field experiments have been conducted to date to demonstrate the effectiveness and limitations associated with the pressure-based leakage detection for carbon storage reservoirs. Here, a distinction is made between field experiments that are designed to quantify the effect of pressure responses to leakage and those that simply collect pressure data as side products. We refer the former category as active monitoring, while the latter as passive monitoring.

This paper presents results from a series of deep subsurface tests conducted 
${ }_{67}$ The reservoir remained idle until Denbury began $\mathrm{CO}_{2}$ flooding for EOR in

68 July 2008. The source of $\mathrm{CO}_{2}$ was produced from a nearby natural source

${ }_{69}$ in Jackson Dome, Mississippi. The Cranfield site was originally selected by 70 SECARB to develop the practice of "stacked storage," which would use the 71 EOR operations to support infrastructure setup, characterization, and public 72 acceptance for longer-term saline storage of $\mathrm{CO}_{2}[16]$. 

94 (CFU31-F2 and CFU31-F3) (Fig. 1). These three wells will be referred to as F1,

${ }_{95}$ F2, and F3 in the rest of this paper. The surface separation distance between

${ }_{96} \mathrm{~F} 1$ and F2 is $69.8 \mathrm{~m}$, and between F2 and F3 it is $29.9 \mathrm{~m}$. The bottom-hole 97 distance between $\mathrm{F} 1$ and $\mathrm{F} 2$ is $60 \mathrm{~m}$; between F1 and F3 it is $93 \mathrm{~m}$; and between

${ }_{98} \mathrm{~F} 2$ and F3 it is $33.5 \mathrm{~m}$. F2 and F3 were completed with fiberglass casing to 99 trending crestal graben) located about 3,010 m below ground surface. The reservoir formation comprises fluvial sandstones and conglomerates of the Cretaceous lower Tuscaloosa Formation, which is underlain by a regional unconformity on top of shales and sandstones of the Dantzler Formation. The regional confining zone overlying the reservoir is $60 \mathrm{~m}$ of the middle Tuscaloosa marine mudstone. The $\mathrm{CO}_{2}$ injection interval at the Cranfield site is locally referred to as the $\mathrm{D}$ and E units, which range from 14 to $24 \mathrm{~m}$ in thickness and were deposited as part of a laterally continuous but internally complex fluvial formation comprised of fining-upward sandstones and conglomerates. Chlorite coatings appear to have preserved porosity and inhibited quartz cementation, but occluded permeability.

The stacking facies pattern of point-bar and channel sand bodies as found in the D-E units can have a significant impact on flow and transport paths, as many previous studies have shown $[24,39]$. The reservoir temperature is about 129 ${ }^{\circ} \mathrm{C}$, and reservoir pressure before $\mathrm{CO}_{2}$-EOR started is around $32 \mathrm{MPa}$, which is close to the original hydrostatic pressure in place. The dip of the reservoir interval ranges from 1 to 3 degrees. More detailed descriptions of the regional and site geology related to Cranfield can be found in Lu et al. [27].

Many of the past research and development activities at the Cranfield site had been conducted at its Detailed Area of Study (DAS) site, which consists of three colinear wells, including one injector (CFU31-F1) and two monitoring wells 22, and F3 in the rest of this paper. The surface separation distance between 9 facilitate electrical resistance tomography (ERT) measurements and other well

The Cranfield reservoir is a four-way structural closure (with a northwest- 
loggings during site characterization. Fig. 2 shows the vertical distributions of permeability and porosity values obtained from core samples, which reflect the vertically and laterally heterogeneous nature of the lower Tuscaloosa fluvial formation. All three wells are located just outside the oil field and completed in the water zone below the oil-water contact.

Injection of $\mathrm{CO}_{2}$ into brine at $\mathrm{F} 1$ was initiated on December 1, 2009 with an initial rate of $175 \mathrm{~kg} / \mathrm{min}$, which was increased gradually to $350 \mathrm{~kg} / \mathrm{min}$. Continuous fluid sampling was carried out during the first month of $\mathrm{CO}_{2}$ injection, and two subsequent tracer tests using sulfur hexafluoride and noble gases were conducted at different injection rates to measure flow velocity changes. A main goal of that experiment was to obtain high-resolution monitoring data as the reservoir went through phase changes. Experimental results indicated that the DAS wells were connected through numerous, separate fluid flow pathways [27]. To confirm storage permanence and track the $\mathrm{CO}_{2}$ plume pattern, crosswell seismic tomography was done before injection started and then 10 months after the initiation of injection [3]. The time-lapse seismic tomography revealed two spatial zones of significant $\mathrm{CO}_{2}$ saturation, which corresponds to zones of elevated permeability in lower Tuscaloosa D-E units (Fig. 2) and are consistent with results from time-lapse sonic logs and the Reservoir Saturation Tool (RST) $\log$.

The injection rate at Cranfield has been about 1 million metric tons per year since 2008 [16]. High-resolution pressure gauges were initially deployed in both the reservoir and the above-zone monitoring interval in a monitoring well (EGL-7) located near the center of the Cranfield site to monitor pressure responses to the initiation of injection. The injection zone gauge showed a pressure increase within days of the start of injection and pressure increased steadily for 3 months, raising the reservoir pressure to approximately $5.2 \mathrm{MPa}$ (754 psi) 
above the initial conditions [31]. Experience gained from EGL-7 suggests that continuous pressure monitoring has merits in capturing high-frequency pressure variations. However, isolating the causes of these variations was challenging using passive monitoring alone because of the ambiguity caused by reservoir operations [16]. In contrast, the time-lapse pulse-testing leakage detection proposed in this study is an appealing, active monitoring technique that is designed to counteract noise interference to pressure signals. In the next section, we describe the main principles underlying pulse testing and provide details on field experimental design and execution.

\section{Methodology}

\subsection{Pulse testing}

Pulse testing was originally introduced to reservoir characterization in the 1960s [20]. Since then, the technology has been demonstrated for crosswell pressure transient testing in many reservoir studies [e.g., 30, 4, 11]. The simplest pulse testing involves the use of square or rectangular pulses. If conditions permit, harmonic pulse testing (HPT) may also be done, in which case sinusoidal excitation to the reservoir is introduced through the pulser well and pressure responses are continuously monitored in both the pulser well and the monitoring well(s). Compared to square pulses, HPT data are easier to analyze because only a single sinusoid is involved per test; however, the test itself is more complicated to administer and requires special equipment to generate sinusoidal rates. So far, HPT has been investigated mainly in analytical and numerical reservoir modeling [14, 2, 36], groundwater applications [33, 7, 12, 34], and laboratory core sample characterization [5].

By design, the interference of instrumentation noise and reservoir operations can be significantly suppressed or even completely eliminated in pulse testing 
by selecting a priori the pulsing periods and, thereby, frequencies of signals. Such is the main advantage of active pressure monitoring over passive pressure monitoring. Moreover, repeating pulse testing at multiple pulsing periods may extract additional information on reservoir properties and improve reservoir parameter estimation, as shown in previous studies $[7,11]$.

Using Fourier expansion, the pulse function applied at an injector can be approximated using superposition of sinusoids, each having a frequency that is a multiple of the fundamental frequency. The corresponding pressure response at a monitoring well can then be approximated as

$$
P(r, t)=\sum_{n=1}^{N} A_{n} \sin \left(n \omega t+\phi_{n}\right),
$$

where $P$ is pressure, $r$ is distance from the pulser, $t$ is elapsed time, $\omega=2 \pi / T$ is the fundamental frequency determined by the pulsing period $T$, and $A_{n}$ and $\phi_{n}$ represent the amplitude and phase associated with the $n$-th sinusoid, respectively. It can be shown through integration that the square pulse contains only odd multiples of $\omega$. According to the Nyquist sampling theorem, the highest frequency that can be resolved is determined by $1 /(2 \Delta t)$, where $\Delta t$ is the sampling interval. Eq. (1) implies that pressure responses acquired from pulse testing can be analyzed using similar frequency-domain techniques developed for $\operatorname{HPT}[2,11,36]$.

Let $P_{i n j}$ and $P_{o b j}$ denote the pressure responses obtained from the injector and a monitoring well, the excitation-response relationship of the reservoir is given by the convolution integral

$$
P_{o b s}=\int_{0}^{t} P_{i n j}(t-\tau) g(\tau) d \tau
$$

where $g(\cdot)$ is the transfer or kernel function. Let $\tilde{P}_{i n j}$ and $\tilde{P}_{\text {obs }}$ represent the 
Fourier transform of $P_{i n j}$ and $P_{o b j}$, the system frequency response function $\mathcal{H}(\omega)$ (i.e., the Fourier transform of $g(\cdot))$ is defined as the ratio between $\tilde{P}_{o b s}$ and $\tilde{P}_{i n j}$, namely, $\mathcal{H}(\omega)=\tilde{P}_{\text {obs }} / \tilde{P}_{i n j}$. The frequency response function depends on mobility, porosity, and total compressibility of the reservoir under study, and thus it provides a characterization of the reservoir's excitation-response behavior in frequency domain. For homogeneous isotropic reservoirs, pulse testing determines the value of mobility-thickness product $(k b / \mu)$ and porositycompressibility-thickness product $\left(\phi c_{t} b\right)$, where $k, b, \mu, \phi$, and $c_{t}$ represent permeability, effective reservoir thickness, viscosity, porosity, and total compressibility, respectively [22]. In this work, the frequency-domain data are used to estimate parameters through an analytical forward model. Each data point in frequency domain represents system responses to a particular frequency embedded in the pulsing signal (see Eq. (1)). By focusing only on those frequencies with meaningful data, the ambiguities related to time domain analyses, especially those caused by noise, can be lessened.

The main idea behind pulse-testing-based leakage detection procedure is that if one or more new leaks occur within the detectable range of an observer, the observer's pressure responses to pulser will be modified, which then leads to an observable deviation in $\mathcal{H}(\omega)$ from its baseline shape. Thus, this technique is similar to time-lapse seismic methods in principle. When deployed as a routine monitoring method, each pulse test without anomaly can in turn serve as the baseline for the next test. The requirement of a baseline is common among timelapse monitoring methods. Alternatively, a forward model can be developed to predict the nominal system behavior (i.e., in absence of leakage) in lieu of the baseline. The latter aspect is examined in the following analyses in Section 4.3.

In a multiphase fluid setting, it is commonly assumed that the injected fluid displaces the ambient fluid in a piston-like fashion such that two fluid banks are 
formed and the saturation gradient within each fluid zone is approximately zero [1]. Theoretical and numerical validation of the time-lapse HPT leakage detection concept have been provided in Sun et al. [35] and Sun et al. [36] for singleand multiphase flows. In general, the amplitude of $\mathcal{H}(\omega)$ decreases monotonically with increasing pulse frequency. Longer pulsing periods may help probe leaks located farther away (provided that the observation well is still sensitive to both the pulser and leaks), but at the expense of longer experiment time. For carbon storage reservoirs, the authors suggested that the fluid condition at observation locations should not change significantly between two HPTs for the time-lapse method to give meaningful results.

The purpose of our Cranfield DAS experiment is to provide a field-scale validation of the pulse-testing leakage detection concept. $\mathrm{CO}_{2}$ flooding at the injector F1 has been ongoing since December 2009. At Cranfield site, the operator injects $\mathrm{CO}_{2}$ continuously rather than using the conventional water-alternating gas EOR strategy. For those reasons, it was expected that the injection interval underneath the DAS site is mostly saturated with supercritical $\mathrm{CO}_{2}$ and the nonlinear effect related to multiphase flows is minimal. Also, fluid conditions between different sets of pulse tests were not expected to change significantly.

\subsection{Field experiment design and procedure}

The field campaign consists of baseline and leak experiments, which were conducted sequentially. Before the field experiments, high-resolution permanent downhole gauges ( Ranger Permanent Hybrid Digital Addressable Surface Read Out Gauge, Ranger Gauge Systems, Sugar Land, Texas, USA) were installed in well F2 and F3 on December 16-17, 2014. The control lines in each well consist of hybrid fiber-optic electrical cables encapsulated in $0.635-\mathrm{cm}(1 / 4-\mathrm{in})$ stainless steel tubing and were installed using a capillary injection unit through a lubricator and packoff. Resolution of the pressure gauge is $68.9 \mathrm{~Pa}(0.01 \mathrm{psi})$ 
and its data polling frequency is set to every 2 sec. As discussed below, these highly sensitive pressure gauges are necessary to detect small pressure anomalies. Records kept by our well management subcontractor (Sandia Technologies, LLC, Houston, Texas, USA) show that the depth of the downhole gauge assembly is 3,221.1 $\mathrm{m}(10,568 \mathrm{ft})$ in $\mathrm{F} 2$ and 3,222.0 $\mathrm{m}(10,571 \mathrm{ft})$ in F3. Ideally, the bottomhole pressure (BHP) at $\mathrm{F} 1$ should also be monitored during the experiment to normalize the frequency response function, $\mathcal{H}(\omega)$. However, it was not an option for this project. Thus, we mainly used the monitoring well data during analyses.

For the baseline, two sets of pulse testing experiments were performed on January 19 and January 20, 2015, one using a 90-min period and the other using a 150-min period. Each period starts with a shutin half cycle (50\% of the time), followed by a constant-rate injection half cycle. These pulses were introduced to F1 by manually turning on/off the wellhead choke valve. F2 was used as the monitoring well in all experiments.

The actual pulse testing does not require additional equipment other than pressure gauges. However, because there is no known leakage pathway at the DAS site, for demonstration F3 was used to create an artificial leak by venting $\mathrm{CO}_{2}$ from its wellhead. For this purpose, a surface venting plumbing system was set up while the baseline experiments were being conducted. The venting system was used to control the leak rate and to connect to a flowback tank for properly disposing of reservoir fluids that flow out with the gas. Fig. 3 shows a schematic design of the venting system. After rising to the wellhead, the $\mathrm{CO}_{2}$ stream goes from the $\mathrm{F} 3$ wing valve into a $2.54-\mathrm{cm}$ (1-in) iron pipe, which is equipped with a filter, a Coriolis flow/density meter (Micro Motion, Emerson Process Management, Boulder, Colorado, USA), and a flow control valve. Finally, the stream discharges into a 5.08 -cm (2-in) pipe connected to the flowback tank that is located more than $15 \mathrm{~m}$ from the wellhead. Pressure 
and temperature sensors are installed at various locations of the venting system to monitor the flow condition. The filter is used to remove solid particles (e.g., drilling mud residues) that rise to the wellhead. To prevent safety hazards, all sensors and the flow meter are wired to an onsite trailer for remote monitoring and data recording, and the flow control valve can also be regulated remotely through an air compressor connected to the valve.

The leak experiments were repeated using the same pulsing periods as those used in the baseline tests, but with the controlled "leak" on all the time. The first leak experiment was started on January 23. Unfortunately, data communication with the downhole gauge in F2 was lost soon after the experiment started. A slickline service company was called in to replace the downhole gauge with a wireline memory gauge. Experiments then resumed one week later. A 90-min leak experiment was performed on January 30 and a 150-min leak experiment was performed the second day. Venting rate from F3 was fixed at 60 $\mathrm{kg} / \mathrm{min}$ during two leak experiments, but sensitivity to smaller leak rates was also studied.

A number of incidents happened during the leak experiments, caused by natural and human factors. First, after a couple of cycles in each leak experiment, formation water somehow got into the F3 wellbore, causing surface venting pipelines to freeze. The experiment had to be stopped to de-ice the pipelines. Second, the filter was briefly clogged on several occasions and needed to be "backwashed" to clean out residues. Third, the first experiment was cut short because of a shortage of field personnel (only Denbury personnel could control F1 valve). The impact of all these interruptions on the pulse testing results will be discussed in Section 4 . 


\subsection{Data processing and parameter estimation}

Pressure data acquired during pulse testing are first detrended before they are transformed to frequency domain using fast Fourier transform (FFT). Also, to mitigate the impact of initial pressure transients, data from the first halfcycle of all experiments are discarded. The baseline experiments are used for two purposes: (a) time-lapse comparison with the subsequent leak experiments and (b) characterization of reservoir parameters in a baseline model. The latter is developed from pressure diffusivity equation given in radial coordinates

$$
\frac{\partial^{2} P}{\partial^{2} r}+\frac{1}{r} \frac{\partial P}{\partial r}=\frac{\phi \mu c_{t}}{k} \frac{\partial P}{\partial t}
$$

subject to initial and boundary conditions

$$
\begin{gathered}
P(r, t=0)=P_{\text {init }}, \\
\lim _{r \rightarrow \infty} P(r, t)=P_{\text {init }}, \\
\left.\frac{2 \pi k b}{\mu} r \frac{\partial P}{\partial r}\right|_{r=r_{w}}=q_{i n j} B,
\end{gathered}
$$

where $P_{\text {init }}$ is initial pressure, $q_{i n j}$ is constant injection rate, $B$ is volumetric formation factor, and the ratio $k /\left(\phi \mu c_{t}\right)$ is diffusivity. Eq. (5) assumes homogeneous formation properties and infinite boundary conditions, which is a simplified representation of the physical system under study. Nevertheless, the simplified model provides a reasonable first-order approximation of the local system immediately surrounding the pulser well. In this case, the nearby oil producers are located much farther away than the distances between DAS wells.

Thus, the imposed boundary conditions are deemed appropriate. The steady periodic solution can be obtained by solving Eq. (3) in frequency domain [36]

$$
\tilde{P}_{o b s}=\frac{\mu B q}{2 \pi k b} \frac{K_{0}\left(\sqrt{j \omega_{D}}\right)}{r_{D} \sqrt{j \omega_{D}} K_{1}\left(r_{D} \sqrt{j \omega_{D}}\right)}, r_{D}=\frac{r_{w}}{r_{O}}, \omega_{D}=\frac{\omega r_{O}^{2} \phi \mu c_{t}}{k}
$$


in which $j$ is the imaginary unit, $r_{w}$ is well radius, $r_{O}$ is the distance between pulser and monitoring well, and $K_{0}$ and $K_{1}$ are the zero-th and first-order modified Bessel function of the second kind. Eq. (5) involves four main parameters, namely, $k, b, c_{t}$, and $\phi$. The unknown parameters are estimated by minimizing the following objective function

$$
\min _{\boldsymbol{\theta}} \sum_{i}\left\{\left(\Lambda_{i}-\left|\tilde{P}\left(\omega_{i}, \boldsymbol{\theta}\right)\right|\right)^{2}+\lambda\left(\Phi_{i}-\angle \tilde{P}\left(\omega_{i}, \boldsymbol{\theta}\right)\right)^{2}\right\}
$$

where $\boldsymbol{\theta}$ is a vector of unknowns; $\Lambda_{i}$ and $\Phi_{i}$ are amplitude and phase data obtained from actual experiments for frequency $\omega_{i} ;\left|\tilde{P}\left(\omega_{i}, \boldsymbol{\theta}\right)\right|$ and $\angle \tilde{P}\left(\omega_{i}, \boldsymbol{\theta}\right)$ denote the amplitude and phase shift of the frequency domain model given in Eq. (5); and $\lambda$ is a weight factor used to scale the two terms in the objective function. The summation is over all amplitude and phase shift data pairs. In this work, the unknown parameters include permeability and the product of porosity and total compressibility (i.e., $\boldsymbol{\theta}=\left[k, \phi c_{t}\right]^{T}$ ), as is commonly done in type curve analyses [25]. The resulting sum of squares problem is solved by using lsqnonlin function in Matlab[29].

\section{Results and discussion}

\subsection{Baseline experiments}

The 90-min baseline pulse testing was initiated at 11:10 on January 19 and lasted for 5 cycles. Each cycle consisted of a 45-min shutin period, followed by a 45 -min period of constant-rate injection at $3,621 \mathrm{bbl} / \mathrm{d}\left(2.83 \times 10^{5}\right.$ standard $\left.\mathrm{m}^{3} / \mathrm{d}\right)$, which is about twice the nominal injection rate $(1,800 \mathrm{bbl} / \mathrm{d})$ that had been used continuously at F1 for at least one month prior to our experiment. After the last shutin period of the experiment, the injection rate was set back to the nominal rate for the night. Before the experiment, the initial reservoir pressure was 4,718 psi (32.53 $\mathrm{MPa})$. The formation factor corresponding to 
the reservoir pressure and temperature is 0.00317 reservoir bbl/bbl. Figs. 4a and $4 \mathrm{c}$ show the raw pressure time series $(1 \mathrm{psi}=6,894.7 \mathrm{~Pa})$ acquired from F2 and F3 for the duration of the experiment. Both plots show a sinusoidal pattern with a mild upward trend. Figs. 4b and 4d show the pressure anomalies obtained after detrending the raw data. The figures suggest that pressure anomalies resulting from pulsing are less than 0.5 psi in both wells, indicating relatively small effective permeability. Nevertheless, the signal-to-noiseratio is strongand instrumentation noise mainly manifests as small oscillations around the sinusoidal waves.

The baseline was repeated for the 150-min cycle on the second day (January 20) using the same injection rates. The test started at 8:25 and lasted for 4 cycles. Figs. $5 \mathrm{a}$ and $5 \mathrm{c}$ show the raw pressure time series obtained from the second pulse test, and Figs. 5b and 5d show the corresponding pressure anomalies. The raw signals show patterns similar to those seen in the 90-min case: a sinusoidal wave with a mild upward trend. In this case, the magnitudes of pressure anomalies are greater because of longer pulsing periods.

Overall, the baseline experiments went smoothly, although the magnitude of reservoir pressure anomalies resulting from pulsing was lower than expected, indicating a relatively low effective permeability. Thus, the high-resolution pressure gauges turned out to be instrumental for picking up the small pressure changes. During the experiments, the monitoring well temperature was rather insensitive to the pulses and is not shown here.

\subsection{Leak experiments}

The 90-min leak experiment started at 8:30 on January 30 and venting of $\mathrm{CO}_{2}$ started at the same time. Fig. 6 shows a typical scene from the leak experiment. The expansion of $\mathrm{CO}_{2}$ from liquid to gas phase absorbs heat . Thus, the pipeline to flowback tank is covered with frost under normal conditions, as 
shown in the picture. However, when $\mathrm{CO}_{2}$ stream also has water and other impurities in it, ice forms inside the pipeline, eventually clogging the $\mathrm{CO}_{2}$ flow.

Fig. 7a shows the raw pressure signals obtained from the 90-min experiment. Fig. 7b shows the BHP at F3 and leak history. Density log measured by the flow meter is shown in Fig. 7c. During the experiment, the venting pipeline was stopped briefly (several minutes) for backwashing and de-icing, which show up as three spikes in Fig. 7b. Between 11:00 and 11:30, the density log shows two slight increases that signal the inflow of heavier formation water into the well column. Because of the personnel issue mentioned in Section 3, the experiment was terminated earlier than planned at 12:15. Fig. $7 \mathrm{~d}$ shows the pressure anomalies after removing a linear trend from the raw pressure signals. For comparison, pressure anomaly time series from the corresponding baseline experiment is superposed. The leak profile is more subdued than that of the no-leak case. The low pressure near 10:55 coincided with the first shutdown for backwash, which caused the pressure to rise earlier than planned.

The 150-min leak experiment started at 8:30 on January 31. Venting was started at 8:10. The experiment went smoothly from the start until about 13:05 when the pipeline became frozen, causing the experiment to shut down for 20 min. The water influx issue became more severe from that point on, as shown in Figs. 8a and 8b and the density log in Fig. 8c. As a result, the analysis was restricted to data collected before 13:00. In this case, Fig. 8d suggests that the deviation from the no-leak counterpart becomes more pronounced after the second full cycle starts. Comparison of Figs. 8a and 8b indicates that F2 is very responsive to BHP changes in F3, indicating good pressure communication between the two wells.

Overall, the two leak experiments turned out to be quite eventful. The original downhole pressure gauges lost communication to surface unit because 
reservoir fluids got inside the stainless steel tubing used for housing the electrical cable. Indeed, several cracks were found on the tubing after the downhole gauge unit was retrieved from F2. The cracks might have been introduced during the installation process or caused by corrosion. Thus, for long-term monitoring, careful considerations must be given not only to the downhole gauge selection, but also to all its accessories, including tubing materials. The unexpected frozen pipe issue caused several mishaps. Apparently, formation water exists in isolated compartments that are outside the established $\mathrm{CO}_{2}$ sweeping zones, five years after the initial $\mathrm{CO}_{2}$ injection. When the pressure at $\mathrm{F} 3$ was reduced locally, either vertical or lateral water flux was activated, leading to influx into the wellbore. Although this issue pertains mainly to the needs of creating an artificial leak in our experiments and not to real-life pulse testing, for future experiments of this kind it is suggested that a separator be used to avoid ice formation in the venting pipe.

\subsection{Time-lapse analyses}

In this subsection, we compare data obtained from baseline and leak experiments. Signal processing is done by first removing a linear trend from the time series and then performing FFT. The resulting residual or pressure anomalies are already shown in Figs. 4, 5 and 7, 8. Because a simple square wave pattern is used in our experiments, amplitudes are dominated by those corresponding to the pulsing frequency, as can be seen from Fig. 9. Thus, only the dominating amplitudes are extracted for parameter estimation. Although other non-zero frequency responses (e.g., multiples of the pulsing frequency) can also be utilized for parameter estimation, [11], they are not pursued here because our main focus is on comparing time-lapse changes in frequency response function at the fundamental pulsing frequencies.

For the baseline experiments, the average phase shifts for each observation 
well are identified from the time series plots shown in Figs.4 and 5 (vertical dotted lines) by using start time of injection and start time of pressure rise. The phase shift data are then normalized by respective pulsing periods. The effective reservoir thickness is set to $25 \mathrm{~m}$ in accordance with previous studies [15]. The scaling factor $\lambda$ is set to 0.01 to scale amplitudes and phase shifts in the objective function because of their magnitude differences, Eq. (6). Using baseline data, the best estimates of $k$ and $\phi c_{t}$ are found to be $1.5 \mathrm{mD}\left(1 \mathrm{mD}=1 \times 10^{-15}\right.$ $\mathrm{m}^{2}$ ) and $9 \times 10^{-12} \mathrm{~Pa}^{-1}$. To facilitate the demonstration of model-based leakage detection, uncertainty analyses is performed using Monte Carlo simulation by sampling from distributions listed in Table 1 . Note that both $k$ and $\phi c_{t}$ are assumed to follow log-normal distributions. Their bounds are set on the basis of prior knowledge. Parameter variance values are chosen in such a way that the amplitude deviations are just outside the confidence bounds of the baseline model (see discussion below). A large number of realizations $(20,000)$ are used in lieu of more delicate sampling schemes because the analytical model is fast to run.

The estimated effective permeability is relatively low but not unreasonable. Previously, Ajo-Franklin et al. [2013] estimated the permeability and porosity values to be $64 \mathrm{mD}$ and 0.25 on the basis of $\mathrm{F} 2$ core samples. It is well known that crosswell testing reflects the effective formation properties of the reservoir volume between the pulser and observation well pair, whereas core sample analysis mainly provides point property estimates and may not be extrapolated to large distances beyond the logged well, especially for heterogeneous formations. On the basis of their U-tube sampling studies, Lu et al. [2012] noted that at the DAS site multiple flow pathways exist over a distance of tens of meters. Hosseini et al. [2013] could not identify a good linear correlation between porosity and $\log$ permeability using core sample data from six wells at Cranfield site. 
Thus, because of the highly complex nature of the fluvial D-E units, it is not surprising that effective permeability estimated using pulse testing data differs from the core sample estimates. However, a key difference between our experiments and the 2009 tracer studies is that the effective reservoir flow paths are saturated with $\mathrm{CO}_{2}$ in our case and thus, we mainly deal with single-phase $\mathrm{CO}_{2}$ flows. The 2009 experiment largely dealt with $\mathrm{CO}_{2}$ invasion in a depleted oil reservoir. The flow path characteristics and travel times are different in the two cases. Indeed, Lu et al. [27] observed that fluid flow velocity between F1 and F2 decreased after 5 months of continuous $\mathrm{CO}_{2}$ flooding because of increased $\mathrm{CO}_{2}$ saturation in the flow pathways or enlarged sweeping paths, or both.

Figs. 10a,b plot the amplitudes of transformed signals as a function of distances from the pulser, as predicted by the calibrated baseline model. For each subplot, the solid line is generated by using the estimated parameters and the shaded area is generated by using the $95 \%$ confidence interval derived from Monte Carlo simulations. Open circles correspond to the baseline data from F2 and F3. Fig. 10 suggests that amplitude decreases with increasing distance from the pulser and longer pulsing periods (i.e., 150-min) tends to boost the amplitude.

Fig. 11 plots the amplitude data obtained from all four pulse testing series acquired from observation well F2. Open symbols correspond to the no-leak experiments, while filled symbols are from the leak experiments. A plot like Fig. 11 provides the essential information required for time-lapse diagnosis of leakage. In this case, the chart shows a clear drop in the amplitude of leak data, as predicted by the analytical models given in [36]. The percentages of amplitude attenuation are $29 \%$ and $20 \%$ in the $150-$ min and $90-$ min experiments. The trend of amplitude attenuation as a function of pulsing frequency $(\omega)$ is also consistent with the analytical solutions presented in Sun et al. [2015], particu- 
larly longer pulsing frequencies reveal larger amplitude attenuation. Thus, Fig.

11 graphically validates the concept of time-lapse leakage detection using DAS data.

As mentioned before, a more challenging situation is when baseline data are not readily available (e.g., at a site with pre-existing leak wells). For these situations, we propose that a statistical hypothesis testing approach be used, which involves a calibrated forward model that also incorporates model uncertainty. The performance of pulse-testing-based leakage detection is then dependent on the model's prediction capability, at least for diagnosing the initial testing results. As an illustration, the variance of $k$ and $\phi c_{t}$ in Table 1 are manually selected such that the leaks can be identified using the baseline model with reasonable confidence. The resulting one-way lower confidence bound, $95 \%$ in this case, is obtained from Monte Carlo simulation and plotted in Fig. 11. For the present case, results suggest that parameter uncertainties should be relatively mild to be able to isolate the presence of leaks. When model uncertainty increases, the difference between deviations caused by model uncertainty and that by leakage becomes blurred. Such difficulty, however, is pertinent to all monitoring technologies requiring the use of predictive models and can only be tackled through acquiring additional site characterization information which, preferably, is acquired through a goal-oriented experimental design approach developed for leakage monitoring [41]. A model that is originally developed for capacity estimation may not possess the sensitivity or accuracy needed for leakage detection uses. It is worthwhile to point out that the shaded area in Fig. 11 is related to model prediction uncertainty, but not sample variance. The latter quantity can only be obtained by repeating the same pulse test configuration several times, and is expected to be much smaller than the range of model prediction uncertainty because it is mainly affected by random fluctuations in 
experimental conditions (e.g., in injection rates), not by model uncertainties.

To simulate the worst-case scenario, the venting rate was fixed at $60 \mathrm{~kg} / \mathrm{min}$ throughout the leak experiments, which is about $20 \%$ of the injection rate. Several sensitivity studies were performed on January 30 after the first leak experiment was terminated. In these experiments, the leak rate at F3 was pulsed while F1 was injecting at a constant nominal rate. The purpose was to observe sensitivity of F2 to different leak rates. Fig. 12 shows an example from the smallest leak rate we tested, which is $10 \mathrm{~kg} / \mathrm{min}$ or $3 \%$ of the injection rate. In this case, the magnitude of filtered signal is less than $0.05 \mathrm{psi}(345 \mathrm{~Pa})$, but the effect of sinusoidal variations can be still observed in F2, indicating that F2 is sensitive to smaller leak rates at F3.

In general, several criteria need to be satisfied for pulsing testing to be used as a detection procedure. First, observation wells need to be sensitive to pulsing. Typical distances between injectors and producers in oil and gas reservoirs range from 100 to $500 \mathrm{~m}$ [28]. The distances between DAS wells fall on the low side of the range, implying longer pulsing periods are probably needed for reservoirs having similar properties as Cranfield. However, we deal with a reservoir with relatively low effective permeability. For more permeable reservoirs, the area of coverage is expected to be larger. Second, observation wells need to be sensitive to leaks. It is important to place monitoring wells at positions that can enhance anomaly discovery through (adaptive) monitoring network design [38]. In a benchmark study, Class et al. [2009] showed that a leak located $100 \mathrm{~m}$ from the injector can reach a maximum leak rate of about $1.2 \mathrm{~kg} / \mathrm{min}$ when the injection rate is $532 \mathrm{~kg} / \mathrm{min}$, which is on the same order of magnitude as the smallest leak rate we tested at DAS. Thus, we expect that the pulsing testing procedure demonstrated here has the potential to be deployed at the well-pattern scale. Finally and probably more importantly, the cause of fre- 
quency response deviation can be attributed to leakage. Although pulse testing is designed to avoid most commonly seen reservoir noise, site-specific conditions need to be considered during the triage phase. The last criterion requires the emplacement of a comprehensive data management such that anomalies can be analyzed and verified through multiple sources of information.

\section{Summary and conclusions}

A series of field experiments were performed at Cranfield's DAS site to demonstrate the concept of time-lapse leakage detection. Results suggest that leakage introduced significant deviations in the reservoir's frequency response function. Thus, pulse testing has the potential to be deployed as a cost-effective leakage detection procedure. Because it is an active monitoring technique, pulse testing can avoid much of the interference caused by reservoir noise. The wide availability of smart sensing technologies and the relatively straightforward testing procedure imply that pulse testing is suitable for long-term monitoring without significant additional investment from field operators. Cranfield's DAS site offers several conditions that favor this particular demonstration, such as the proximity of the three wells, the relatively stable flow conditions after 5 years of $\mathrm{CO}_{2}$ flooding, and the small impact of nearby production activities. The low permeability of the reservoir may have smoothed the pressure perturbations and made them appear more sinusoidal, but it also dampened the observed responses. In our case, the limited field access time prevented a more comprehensive set of leakage experiments from being done. In the future, we hope this simple technique can be tested by more researchers and reservoir operators. 


\section{Acknowledgments}

This work was supported by the U.S. Department of Energy, National Energy

Technology Laboratory under grant DE-FE0012231. The authors are grateful to the following individuals for their help during the field experiments: Denbury field technicians; Mr. Ramon Trevino, the SECARB project manager at the Bureau of Economic Geology; Mr. Paul Cook and Alex Morales at Lawrence Berkeley National Lab; Mr. Kirk Delaune at Sandia Technologies, LLC; and NETL project manager Mr. Brian Dressel. The authors are thankful to the two reviewers (Drs. Michael Cardiff and Peter Fokker) for their constructive comments during the review of the original manuscript.

\section{References}

[1] Abbaszadeh, M., Kamal, M., 1989. Pressure-transient testing of waterinjection wells. SPE reservoir engineering 4 (01), 115-124.

[2] Ahn, S., Horne, R. N., 2010. Estimating permeability distributions from pressure pulse testing. In: SPE Annual Technical Conference and Exhibition. Society of Petroleum Engineers.

[3] Ajo-Franklin, J., Peterson, J., Doetsch, J., Daley, T., 2013. High-resolution characterization of a co 2 plume using crosswell seismic tomography: Cranfield, ms, usa. International Journal of Greenhouse Gas Control 18, 497509.

[4] Beliveau, D., 1989. Pressure transients characterize fractured midale unit. Journal of petroleum technology 41 (12), 1-354.

[5] Bernabé, Y., Mok, U., Evans, B., 2006. A note on the oscillating flow method for measuring rock permeability. International journal of rock mechanics and mining sciences 43 (2), 311-316. 
[6] Birkholzer, J. T., Oldenburg, C. M., Zhou, Q., 2015. Co 2 migration and pressure evolution in deep saline aquifers. International Journal of Greenhouse Gas Control.

[7] Cardiff, M., Bakhos, T., Kitanidis, P., Barrash, W., 2013. Aquifer heterogeneity characterization with oscillatory pumping: Sensitivity analysis and imaging potential. Water Resources Research 49 (9), 5395-5410.

[8] Cihan, A., Zhou, Q., Birkholzer, J. T., 2011. Analytical solutions for pressure perturbation and fluid leakage through aquitards and wells in multilayered-aquifer systems. Water Resources Research 47 (10).

[9] Class, H., Ebigbo, A., Helmig, R., Dahle, H. K., Nordbotten, J. M., Celia, M. A., Audigane, P., Darcis, M., Ennis-King, J., Fan, Y., et al., 2009. A benchmark study on problems related to co2 storage in geologic formations. Computational Geosciences 13 (4), 409-434.

[10] Dempsey, D., Kelkar, S., Pawar, R., 2014. Passive injection: A strategy for mitigating reservoir pressurization, induced seismicity and brine migration in geologic co 2 storage. International Journal of Greenhouse Gas Control $28,96-113$.

[11] Fokker, P. A., Verga, F., 2011. Application of harmonic pulse testing to water-oil displacement. Journal of Petroleum Science and Engineering 79 (3), 125-134.

[12] Guiltinan, E., Becker, M. W., 2015. Measuring well hydraulic connectivity in fractured bedrock using periodic slug tests. Journal of Hydrology 521, $100-107$.

[13] Heath, J. E., McKenna, S. A., Dewers, T. A., Roach, J. D., Kobos, P. H., 2014. Multiwell co2 injectivity: Impact of boundary conditions and brine 
extraction on geologic co2 storage efficiency and pressure buildup. Environmental science \& technology 48 (2), 1067-1074.

[14] Hollaender, F., Hammond, P. S., Gringarten, A. C., 2002. Harmonic testing for continuous well and reservoir monitoring. In: SPE Annual Technical Conference and Exhibition. Society of Petroleum Engineers.

[15] Hosseini, S. A., Lashgari, H., Choi, J. W., Nicot, J.-P., Lu, J., Hovorka, S. D., 2013. Static and dynamic reservoir modeling for geological co2 sequestration at cranfield, mississippi, usa. International Journal of Greenhouse Gas Control 18, 449-462.

[16] Hovorka, S. D., Meckel, T. A., Treviño, R. H., 2013. Monitoring a large-volume injection at cranfield, mississippi - project design and recommendations. International Journal of Greenhouse Gas Control 18 (0), 345 $-360$.

URL http://www.sciencedirect.com/science/article/pii/S1750583613001527

[17] Hu, L., Bayer, P., Alt-Epping, P., Tatomir, A., Sauter, M., Brauchler, R., 2015. Time-lapse pressure tomography for characterizing co 2 plume evolution in a deep saline aquifer. International Journal of Greenhouse Gas Control 39, 91-106.

[18] IEA, 2013. Technology roadmap: Carbon capture and storage, 2013 edition. Tech. rep., International Energy Agency, Paris, France.

[19] Jenkins, C., Chadwick, A., Hovorka, S. D., 2015. The state of the art in monitoring and verification - ten years on. International Journal of Greenhouse Gas Control (0), -. URL http://www.sciencedirect.com/science/article/pii/S1750583615001723

[20] Johnson, C. R., Greenkorn, R., Woods, E., et al., 1966. Pulse-testing: a 
new method for describing reservoir flow properties between wells. Journal of Petroleum Technology 18 (12), 1-599.

[21] Jung, Y., Zhou, Q., Birkholzer, J. T., 2013. Early detection of brine and co 2 leakage through abandoned wells using pressure and surface-deformation monitoring data: Concept and demonstration. Advances in Water Resources $62,555-569$.

[22] Kamal, M. M., 1983. Interference and pulse testing-a review. Journal of Petroleum Technology 35 (12), 2-257.

[23] Kang, M., Nordbotten, J. M., Doster, F., Celia, M. A., 2014. Analytical solutions for two-phase subsurface flow to a leaky fault considering vertical flow effects and fault properties. Water Resources Research 50 (4), 35363552.

[24] Knudby, C., Carrera, J., 2005. On the relationship between indicators of geostatistical, flow and transport connectivity. Advances in Water Resources 28 (4), 405-421.

[25] Lee, J., Rollins, J. B., Spivey, J. P., 2003. Pressure transient testing. Richardson, Tex.: Henry L. Doherty Memorial Fund of AIME, Society of Petroleum Engineers.

[26] Lewicki, J., Oldenburg, C., Dobeck, L., Spangler, L., 2007. Surface co2 leakage during two shallow subsurface co2 releases. Geophysical Research Letters 34 (24).

[27] Lu, J., Cook, P. J., Hosseini, S. A., Yang, C., Romanak, K. D., Zhang, T., Freifeld, B. M., Smyth, R. C., Zeng, H., Hovorka, S. D., 2012. Complex fluid flow revealed by monitoring co2 injection in a fluvial formation. Journal of Geophysical Research: Solid Earth (1978-2012) 117 (B3). 
[28] Lyons, W. C., Plisga, G. J., 2011. Standard handbook of petroleum and natural gas engineering, 2nd Edition. Gulf Professional Publishing, Burlington, MA.

[29] Math Works, 2015. Matlab user manual version r2015b. Math Works Incorporation, Natick, MA.

[30] McKinley, R., Vela, S., Carlton, L., 1968. A field application of pulse-testing for detailed reservoir description. Journal of Petroleum Technology 20 (03), $313-321$.

[31] Meckel, T., Hovorka, S., Kalyanaraman, N., 2008. Continuous pressure monitoring for large volume co2 injections. In: 9th International Conference on Greenhouse Gas Control Technologies (GHGT-9), Washington, DC. pp. $16-20$.

[32] Nordbotten, J. M., Celia, M. A., Bachu, S., Dahle, H. K., 2005. Semianalytical solution for co2 leakage through an abandoned well. Environmental Science \& Technology 39 (2), 602-611, pMID: 15707061.

URL http://dx.doi.org/10.1021/es035338i

[33] Rasmussen, T. C., Haborak, K. G., Young, M. H., 2003. Estimating aquifer hydraulic properties using sinusoidal pumping at the savannah river site, south carolina, usa. Hydrogeology Journal 11 (4), 466-482.

[34] Renner, J., Messar, M., 2006. Periodic pumping tests. Geophysical Journal International 167 (1), 479-493.

[35] Sun, A. Y., Kianinejad, A., Lu, J., Hovorka, S., 2014. A frequency-domain diagnosis tool for early leakage detection at geologic carbon sequestration sites. Energy Procedia 63, 4051-4061. 
[36] Sun, A. Y., Lu, J., Hovorka, S., 2015. A harmonic pulse testing method for leakage detection in deep subsurface storage formations. Water Resources.

[37] Sun, A. Y., Nicot, J.-P., 2012. Inversion of pressure anomaly data for detecting leakage at geologic carbon sequestration sites. Advances in Water Resources 44, 20-29.

[38] Sun, A. Y., Nicot, J.-P., Zhang, X., 2013. Optimal design of pressure-based, leakage detection monitoring networks for geologic carbon sequestration repositories. International Journal of Greenhouse Gas Control 19, 251-261.

[39] Sun, A. Y., Ritzi, R. W., Sims, D. W., 2008. Characterization and modeling of spatial variability in a complex alluvial aquifer: Implications on solute transport. Water Resources Research 44 (4).

[40] Sun, A. Y., Zeidouni, M., Nicot, J.-P., Lu, Z., Zhang, D., 2013. Assessing leakage detectability at geologic co 2 sequestration sites using the probabilistic collocation method. Advances in Water Resources 56, 49-60.

[41] Sun, N.-Z., Sun, A. Y., 2015. Model Calibration and Parameter Estimation: For Environmental and Water Resource Systems. Springer.

[42] Trautz, R. C., Pugh, J. D., Varadharajan, C., Zheng, L., Bianchi, M., Nico, P. S., Spycher, N. F., Newell, D. L., Esposito, R. A., Wu, Y., et al., 2012. Effect of dissolved co2 on a shallow groundwater system: a controlled release field experiment. Environmental science \& technology 47 (1), 298305. 
Tables

Table 1: Prior statistics used for Monte Carlo simulation

\begin{tabular}{|c|c|c|c|c|c|}
\hline Parameter & Distribution & Mean & Std Dev & Lower Bound & Upper Bound \\
\hline \hline $\log (k)$ & Normal & 0.37 & 0.55 & -4.61 & 4.61 \\
\hline $\log \left[\left(\phi c_{t}\right) 10^{10}\right]$ & Normal & -2.43 & 0.25 & -6.91 & 1.61 \\
\hline
\end{tabular}

Figure Captions

Fig. 1.Areal view of the Detailed Area of Study at Cranfield site (Lon: -91.141으, Lat: $31.564^{\circ}$ ), which consists of an injector (F1) and two monitoring wells (F2 and F3). During leak experiments, F3 was used as a "leaky" well. Locations of the flowback tank and trailer area are also labeled.

Fig. 2. Porosity and permeability profiles obtained from core sample analyses for ( $\mathrm{a}, \mathrm{b}) \mathrm{F} 2$ and $(\mathrm{c}, \mathrm{d}) \mathrm{F} 3$.

Fig. 3. Schematic drawing of leak experiment setup: $\mathrm{CO}_{2}$ vents from $\mathrm{F} 3$ wellhead into the surface plumbing system consisted of a filter, a flow meter, a leak valve, and multiple pressure and temperature sensors. A flowback tank (see Figure 1) is used to collect formation fluids that may rise to the surface during venting.

Fig. 4. Results of 90-min baseline experiment: (a) the square wave injection pattern imposed at F1 (right axis) and raw pressure data observed in F2 (left axis); (b) filtered pressure anomalies in F2; (c) raw pressure data acquired from F3; and (d) filtered pressure anomalies in F3. Vertical dotted lines in (a) and (c) indicate lags between injection starts and observed pressure rises. The time axis corresponding to actual experimental time.

Fig. 5. Results of 150-min baseline experiment: (a) square injection pattern (right axis) and resulting raw pressure data observed in F2 (left axis) ; (b) filtered pressure anomalies in F2; (c) raw pressure data in F3; and (d) filtered 
pressure anomalies in F3. Vertical dotted lines indicate lags between injection start times and observed pressure rises.

Fig. 6. Scene from leak experiment in session, in which the venting pipeline is covered with frost, liquid flowback tank is in the far back, and a slickline pressure gauge is used to monitor downhole pressure.

Fig. 7. Results from 90-min leak experiment: (a) raw data observed in F2 (left axis) and imposed square pulses (right axis); (b) BHP in F3 (left axis) and surface leak rate (right axis); (c) density log measured by flow meter; and (d) filtered pressure anomalies in F2 for both leak and baseline experiments.

Fig. 8. Results from 150-min leak experiment: (a) raw data collected in F2 (left axis) and square pulses (right axis); (b) BHP in F3 (left axis) and surface leak rate (right axis); (c) density log obtained by flow meter; and (d) filtered pressure anomalies in F2.

Fig. 9. Amplitude vs. frequency for the 90-min pulse experiment for F2 and F3, which show the dominating amplitudes occur at the base pulsing frequency. Fig. 10. Amplitude of observed pulsing signals as a function of distance from F1 for (a) 90-min and (b) 150-min pulsing period. Open symbols on each plot correspond to data obtained from F2 and F3. Shaded areas represent confidence intervals estimated from Monte Carlo simulation, solid line corresponds to model values calculated using estimated parameters.

Fig. 11. Leak (filled symbols) caused significant deviation in amplitudes of frequency response function as compared to the no-leak case (open symbols). Solid line is calculated using estimated reservoir parameter values and shaded area is formed by using lower $95 \%$ confidence bound.

Fig. 12. A test used to test sensitivity of F2 to lower venting rates in F3: (a) filtered pressure response, and (b) BHP at F3 (left axis) and leak rate (right axis). A pulse like leak rate was imposed at F3. 


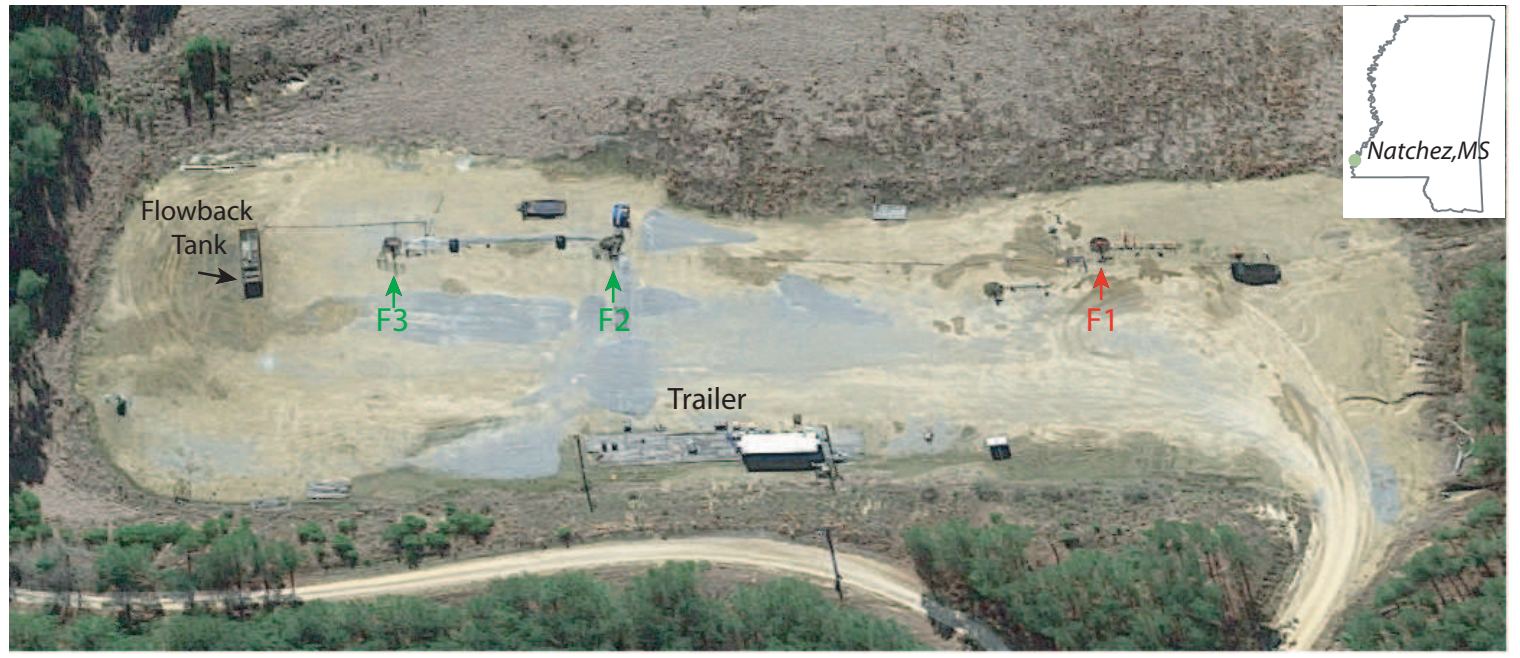

Figure 1: Areal view of the Detailed Area of Study at Cranfield site (Lon: $-91.141^{\circ}$, Lat: $31.564^{\circ}$ ), which consists of an injector (F1) and two monitoring wells (F2 and F3). During leak experiments, F3 was used as a "leaky" well. Locations of the flowback tank and trailer area are also labeled. 
CFU-F2

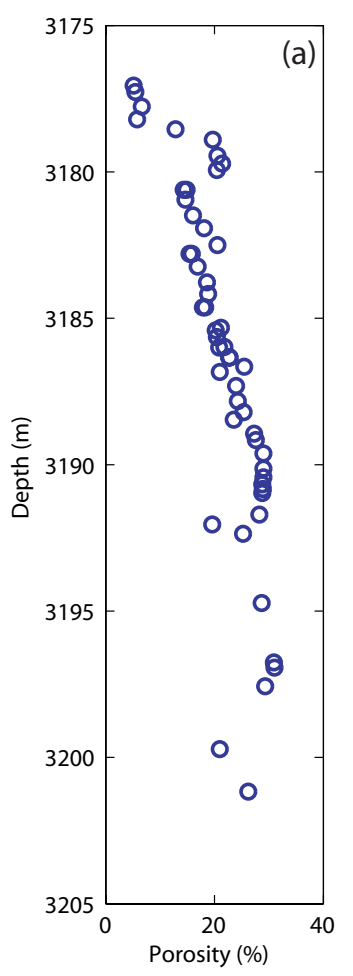

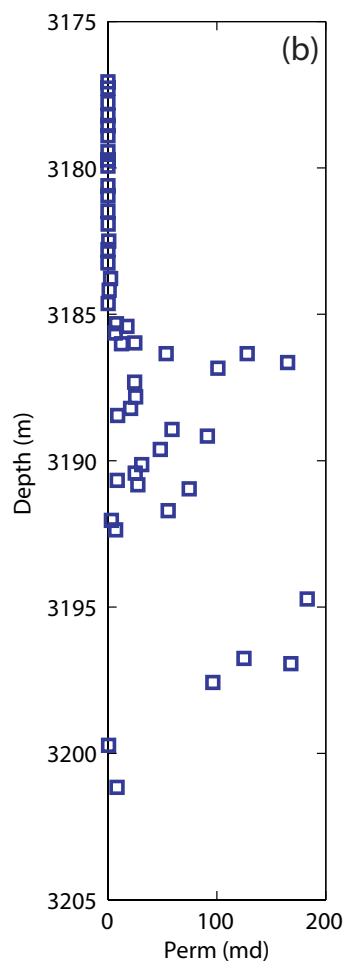

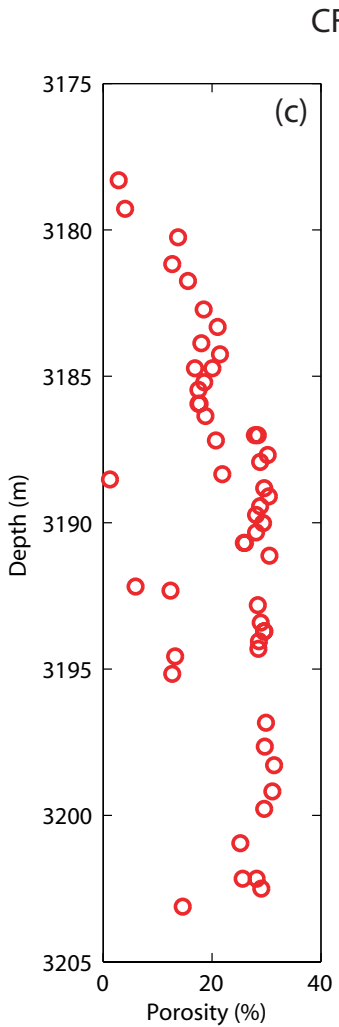

CFU-F3

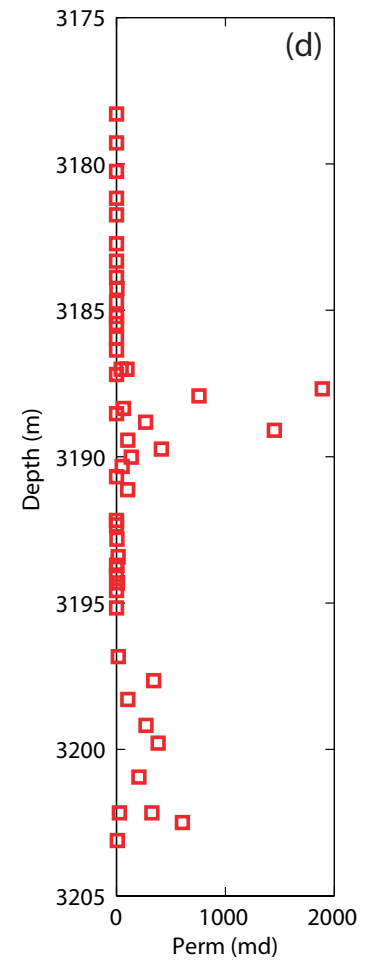

Figure 2: Porosity and permeability profiles obtained from core sample analyses for $(\mathrm{a}, \mathrm{b}) \mathrm{F} 2$ and (c, d) F3. 


\section{Equipment @ F3}

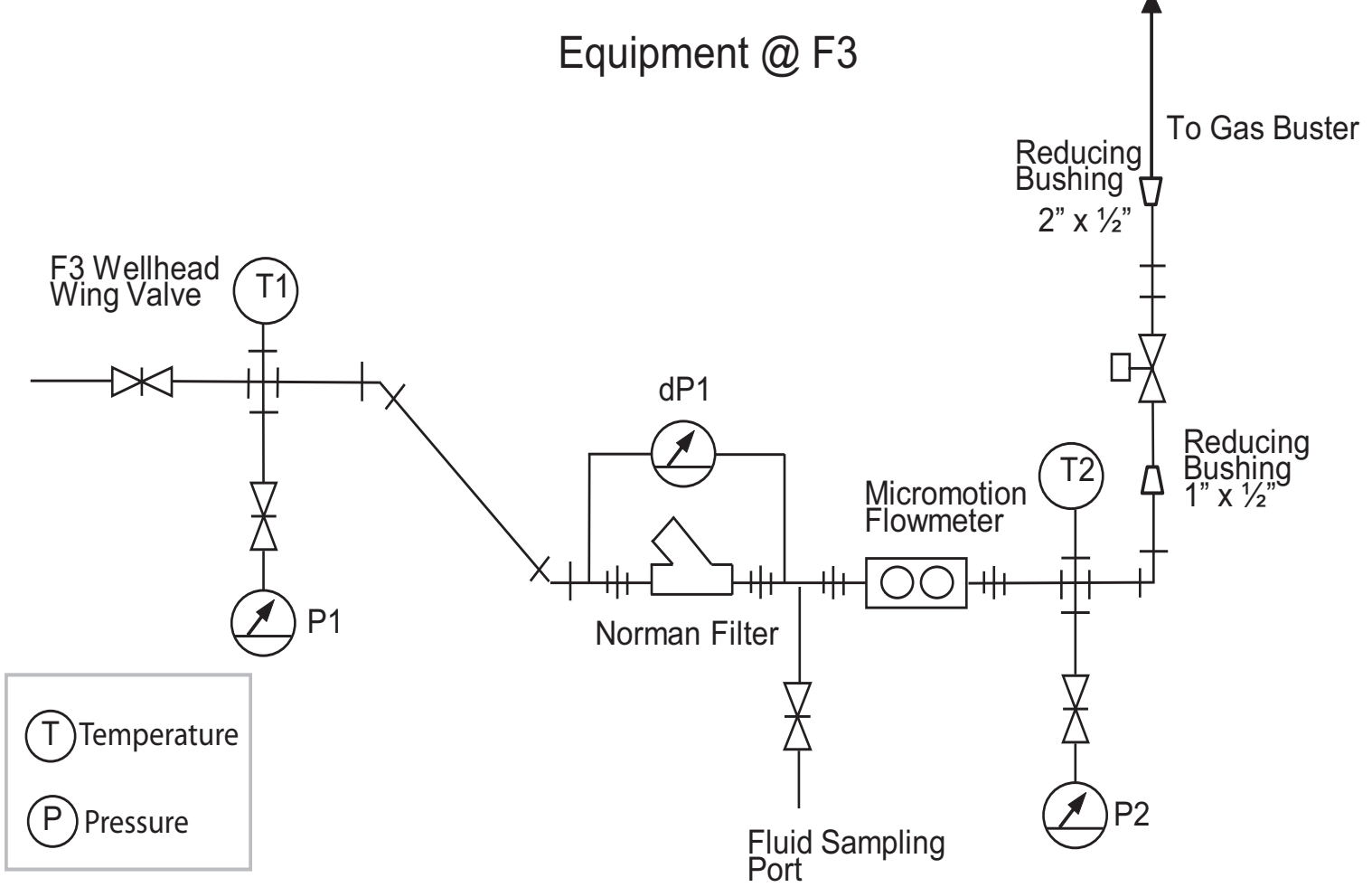

Figure 3: Fig. 3. Schematic drawing of leak experiment setup: $\mathrm{CO}_{2}$ vents from F3 wellhead into the surface plumbing system consisted of a filter, a flow meter, a leak valve, and multiple pressure and temperature sensors. A flowback tank (see Figure 1) is used to collect formation fluids that may rise to the surface during venting. 
(a) 90-min baseline @F2, raw data

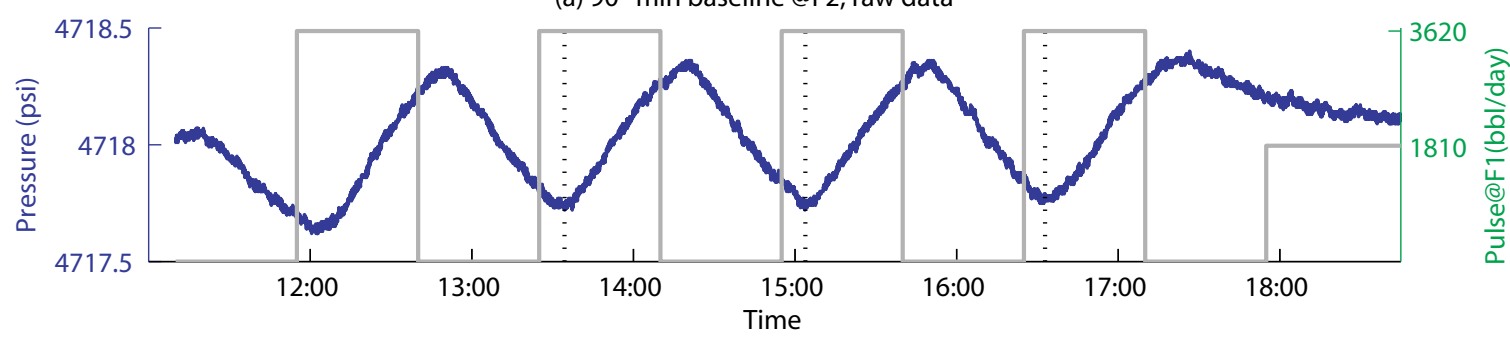

(b) $\Delta \mathrm{P} @ \mathrm{~F} 2$, after trend removal

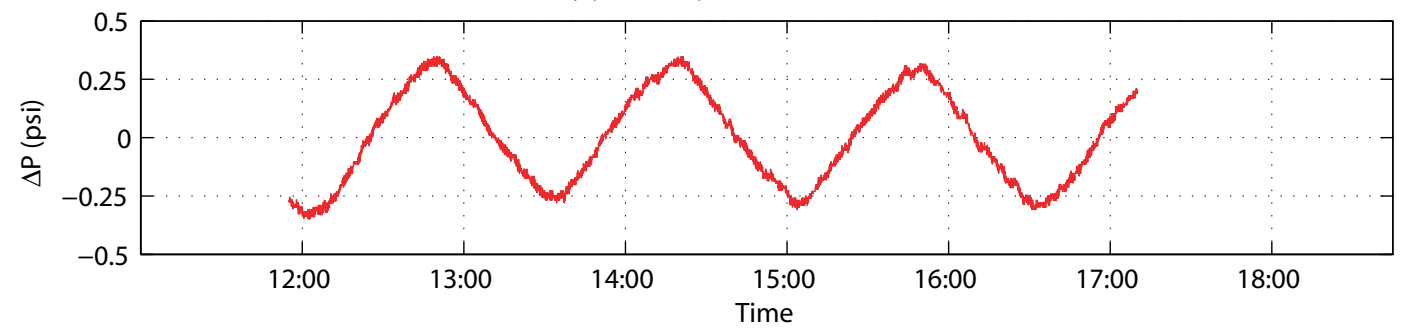

(c) 90-min baseline @F3, raw data

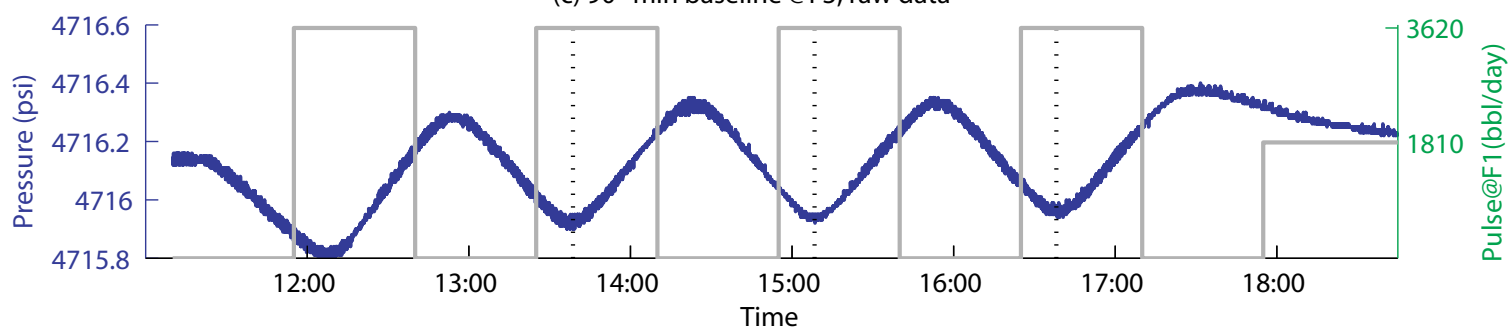

(d) $\Delta \mathrm{P} @ \mathrm{~F} 3$, after trend removal

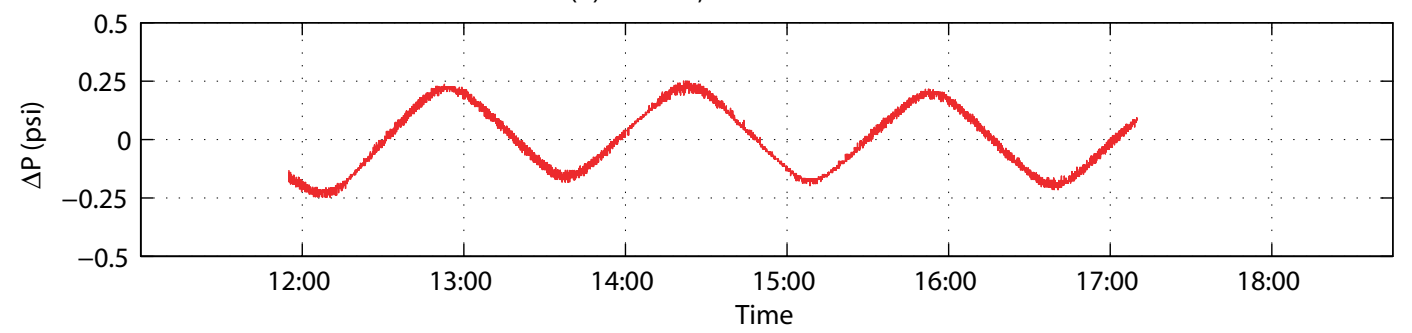

Figure 4: Results of 90-min baseline experiment: (a) the square wave injection pattern imposed at F1 (right axis) and raw pressure data observed in F2 (left axis) ; (b) filtered pressure anomalies in F2; (c) raw pressure data acquired from F3; and (d) filtered pressure anomalies in F3. Vertical dotted lines in (a) and (c) indicate lags between injection starts and observed pressure rises. The time axis corresponding to actual experimental time. 
(a) 150-min baseline @F2, raw data

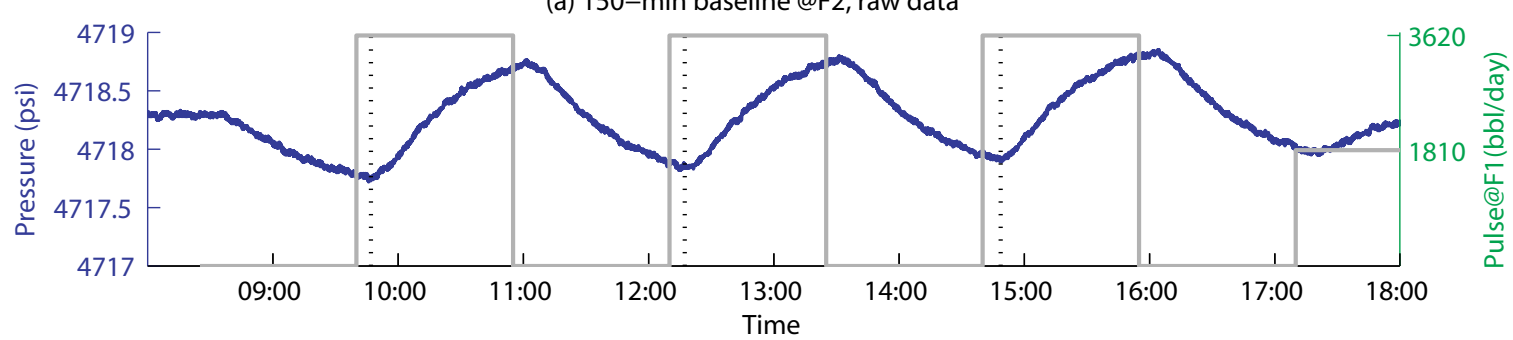

(b) $\Delta \mathrm{P} @ \mathrm{~F} 2$, after trend removal

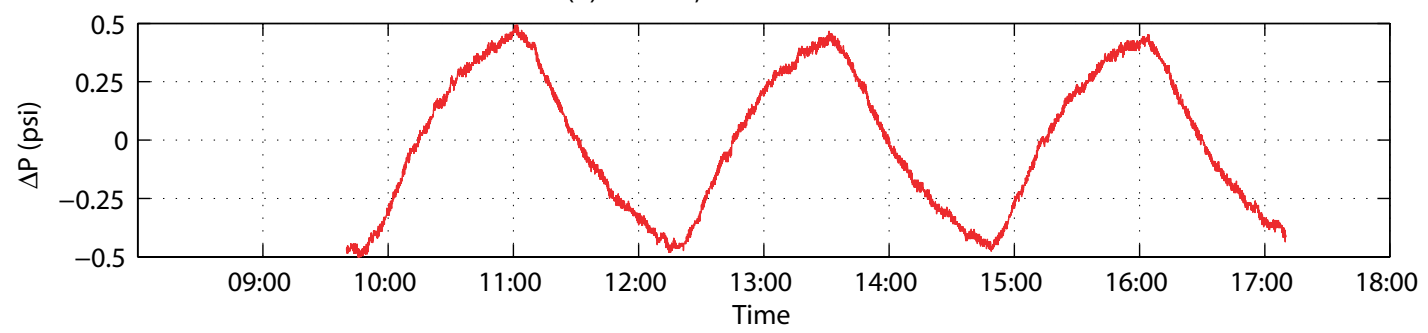

(c) 150-min baseline @F3, raw data

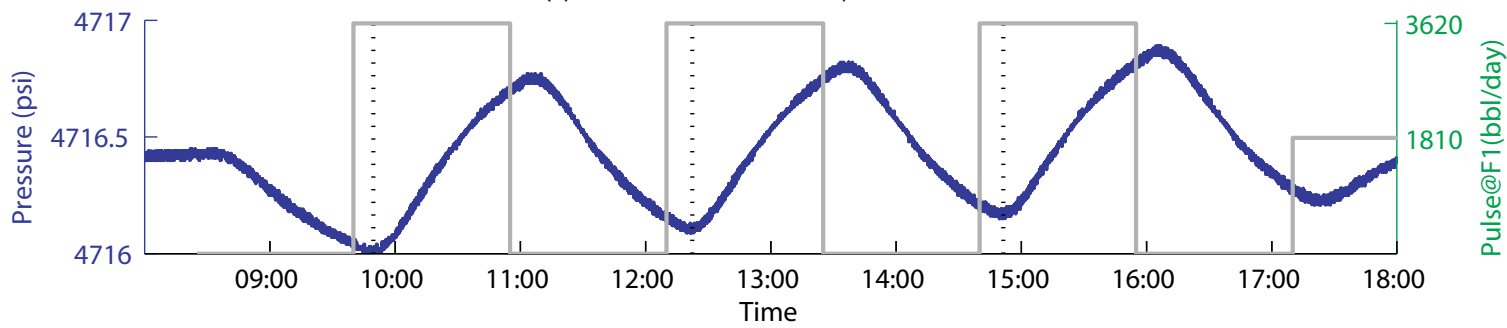

(d) $\Delta \mathrm{P} @ \mathrm{~F} 3$, after trend removal

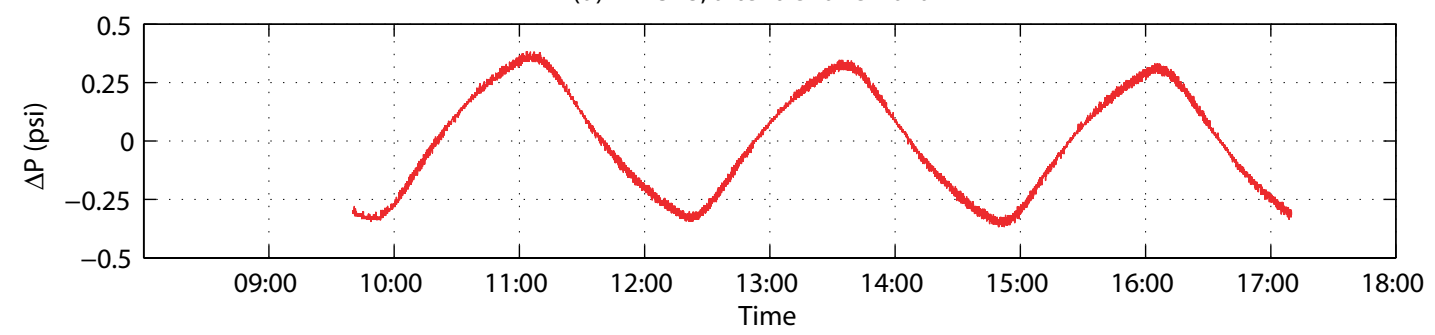

Figure 5: Results of 150-min baseline experiment: (a) square injection pattern (right axis) and resulting raw pressure data observed in F2 (left axis); (b) filtered pressure anomalies in F2; (c) raw pressure data in F3; and (d) filtered pressure anomalies in F3. Vertical dotted

lines indicate lags between injection start times and observed pressure rises. 
F3 Wellhead Flowback Tank

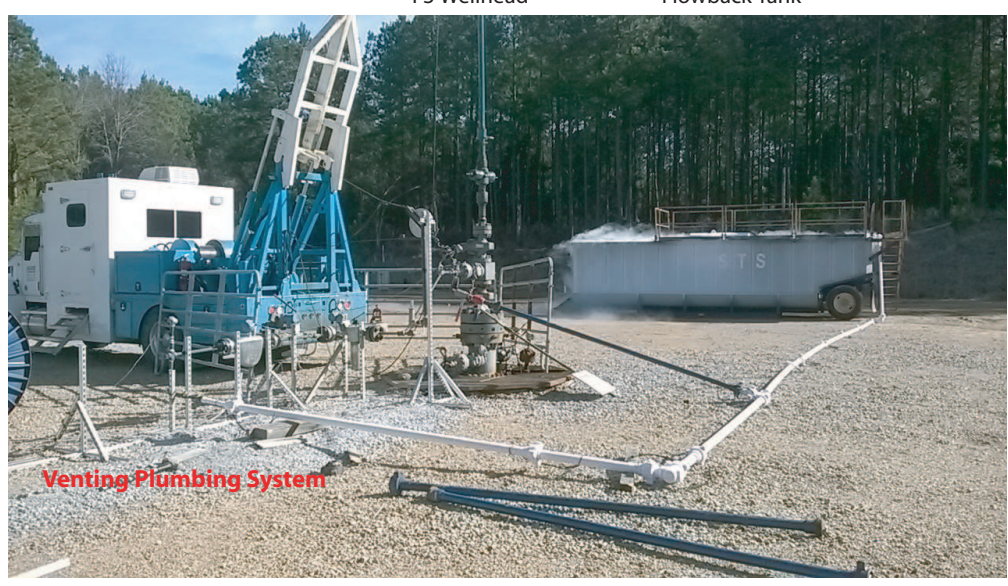

Figure 6: Scene from leak experiment in session, in which the venting pipeline is covered with frost, liquid flowback tank is in the far back, and a slickline pressure gauge is used to monitor downhole pressure. 
(a) 90-min leak test @F2
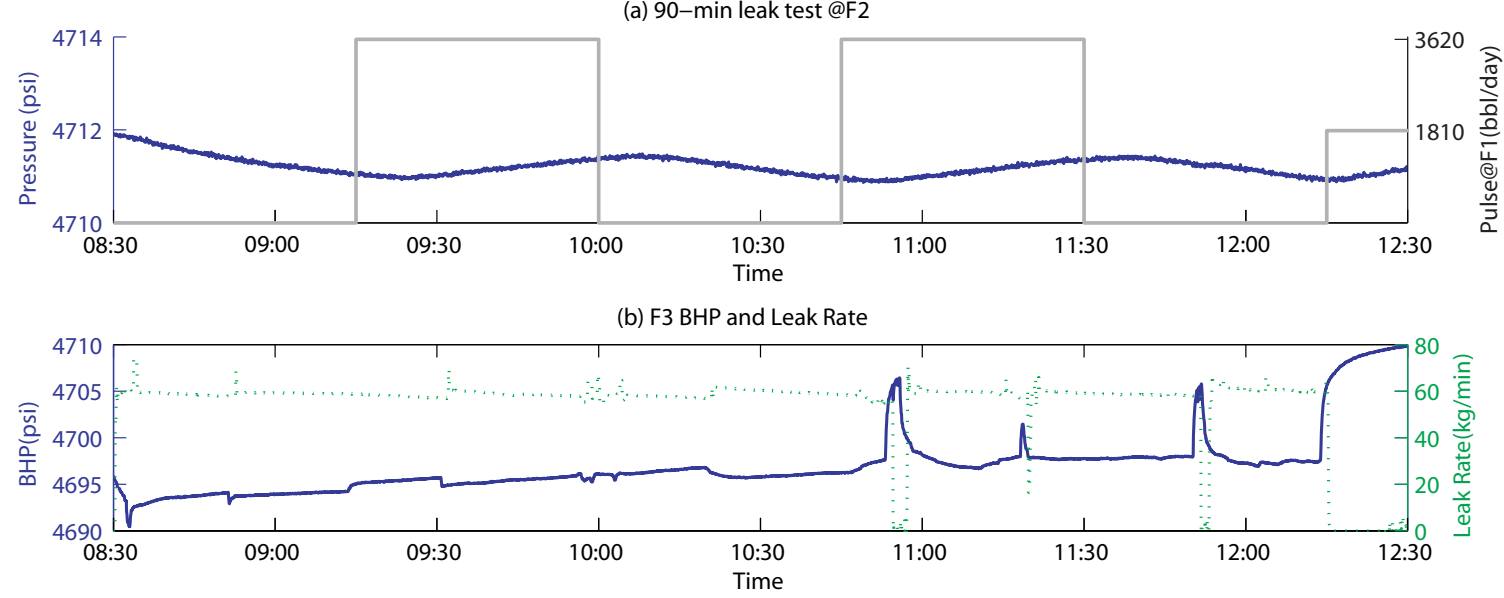

(c) Density log

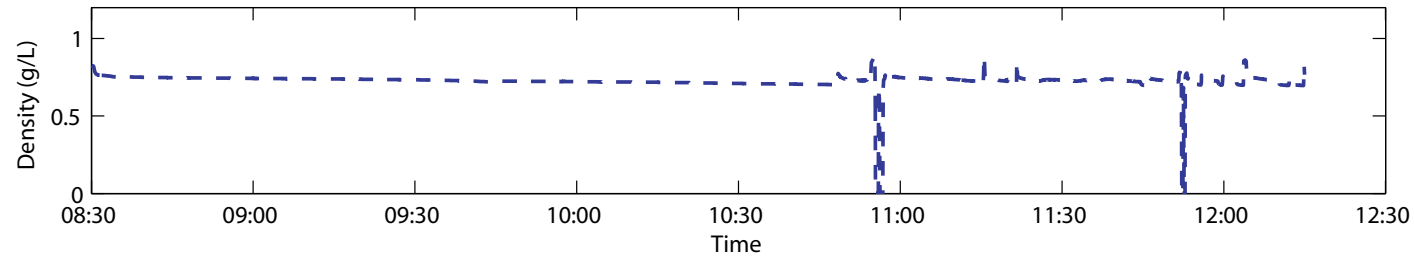

(d) $\Delta \mathrm{P} @ \mathrm{~F} 2$, after trend removal

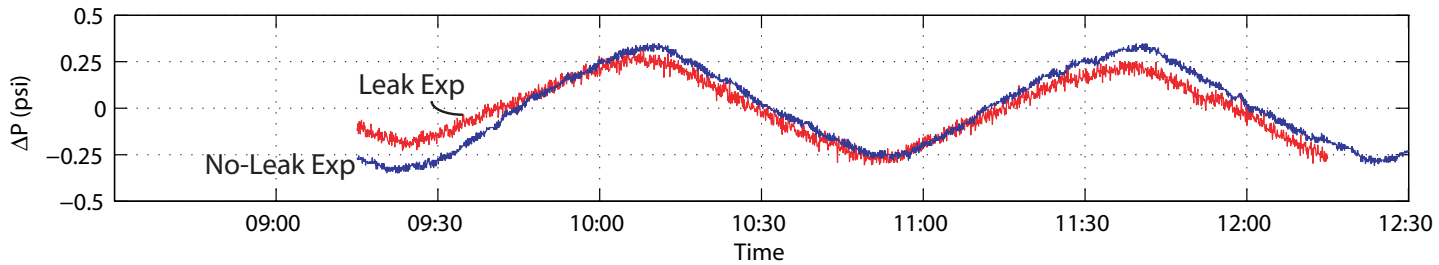

Figure 7: Results from 90-min leak experiment: (a) raw data observed in F2 (left axis) and imposed square pulses (right axis); (b) BHP in F3 (left axis) and surface leak rate (right axis); (c) density log measured by flow meter; and (d) filtered pressure anomalies in F2 for both leak and baseline experiments. 

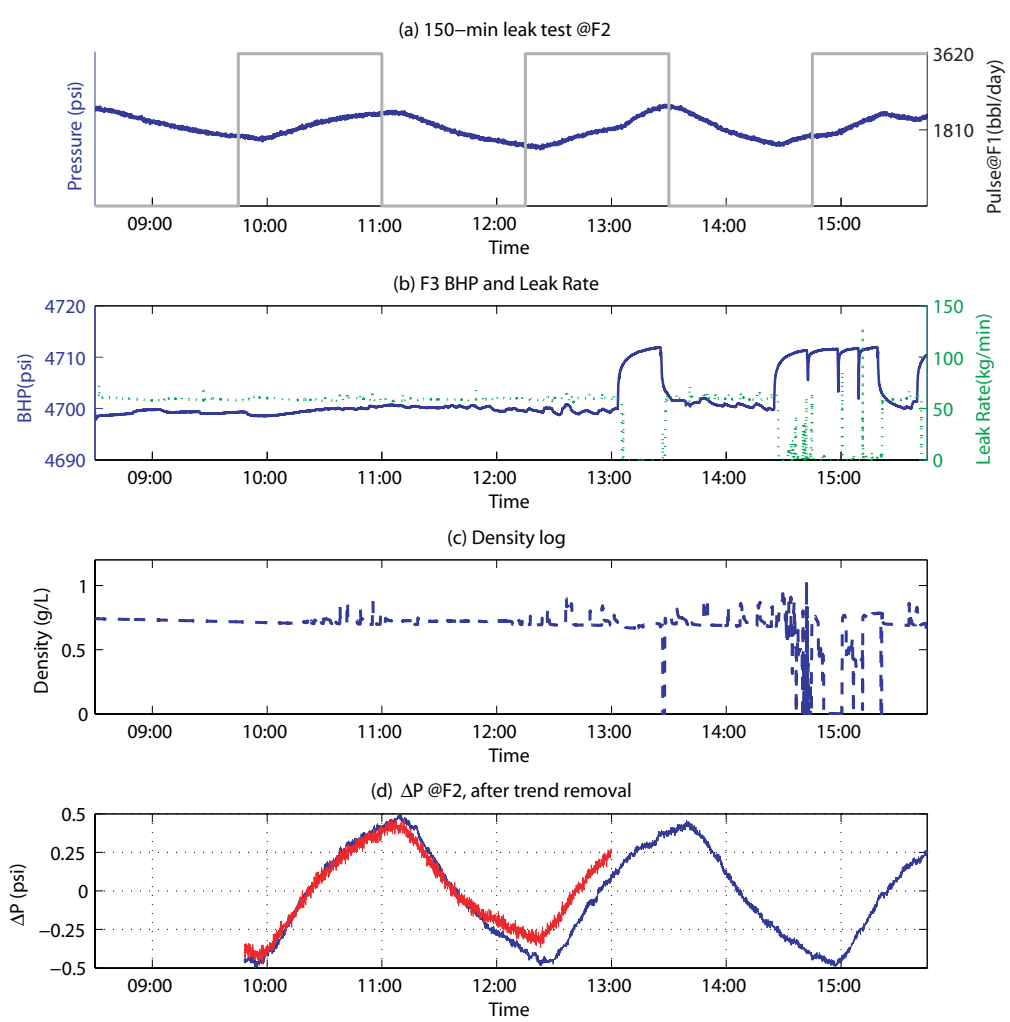

Figure 8: Results from 150-min leak experiment: (a) raw data collected in F2 (left axis) and square pulses (right axis); (b) BHP in F3 (left axis) and surface leak rate (right axis); (c) density log obtained by flow meter; and (d) filtered pressure anomalies in F2. 


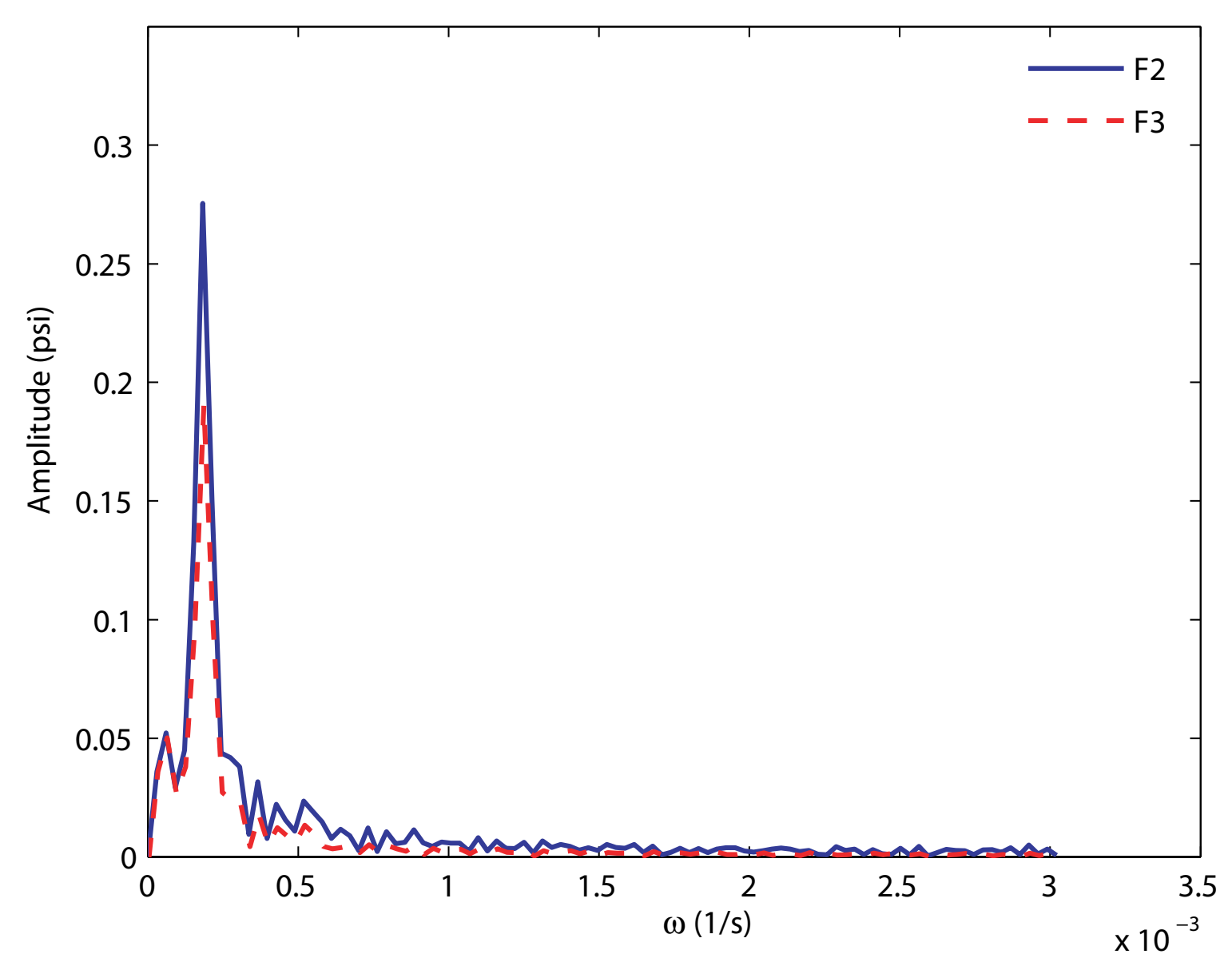

Figure 9: Amplitude vs. frequency for the 90-min pulse experiment for F2 and F3, which show the dominating amplitudes occur at the base pulsing frequency. 

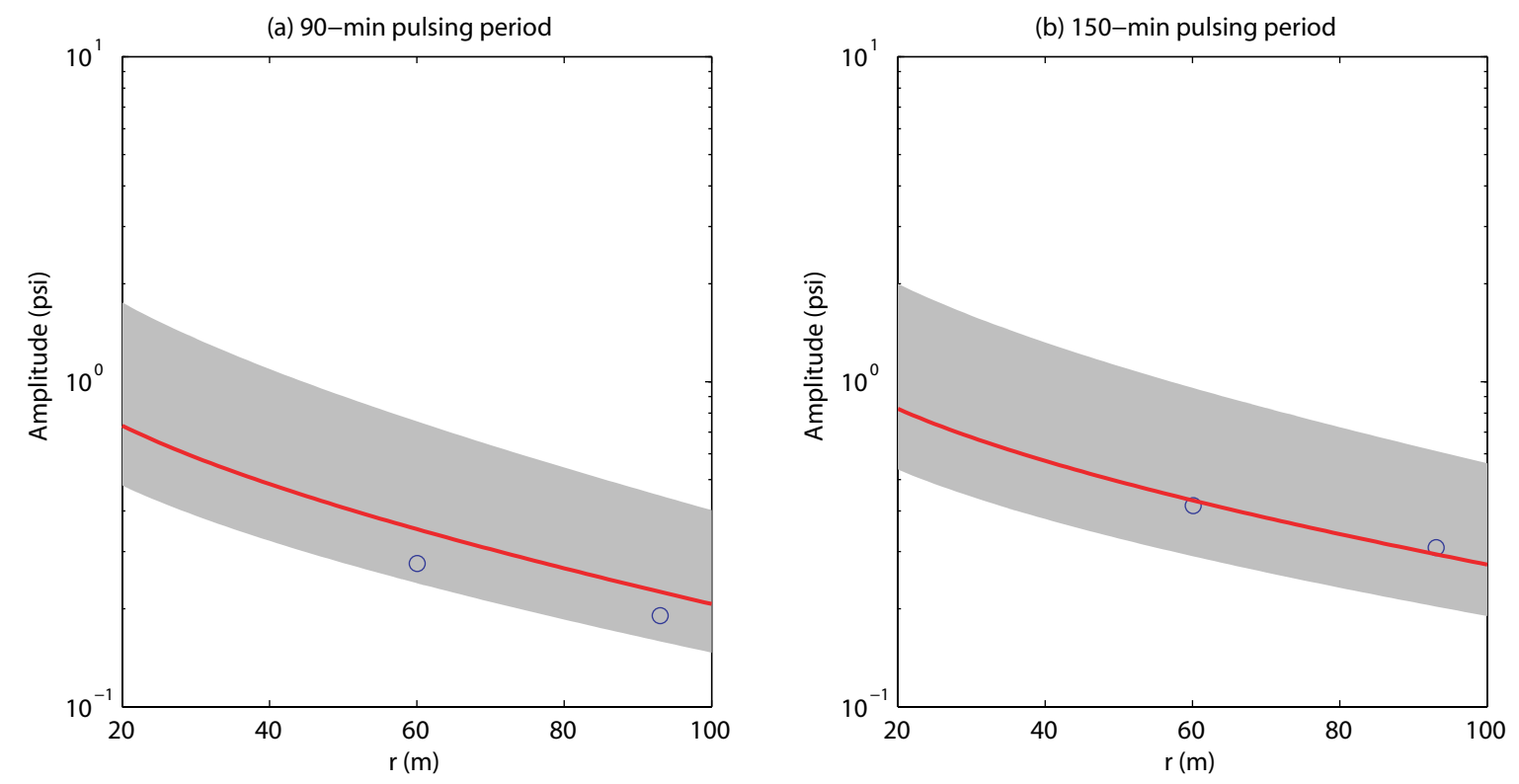

Figure 10: Amplitude of observed pulsing signals as a function of distance from F1 for (a) 90-min and (b) 150-min pulsing period. Open symbols on each plot correspond to data obtained from F2 and F3. Shaded areas represent confidence intervals estimated from Monte Carlo simulation, solid line corresponds to model values calculated using estimated parameters. 


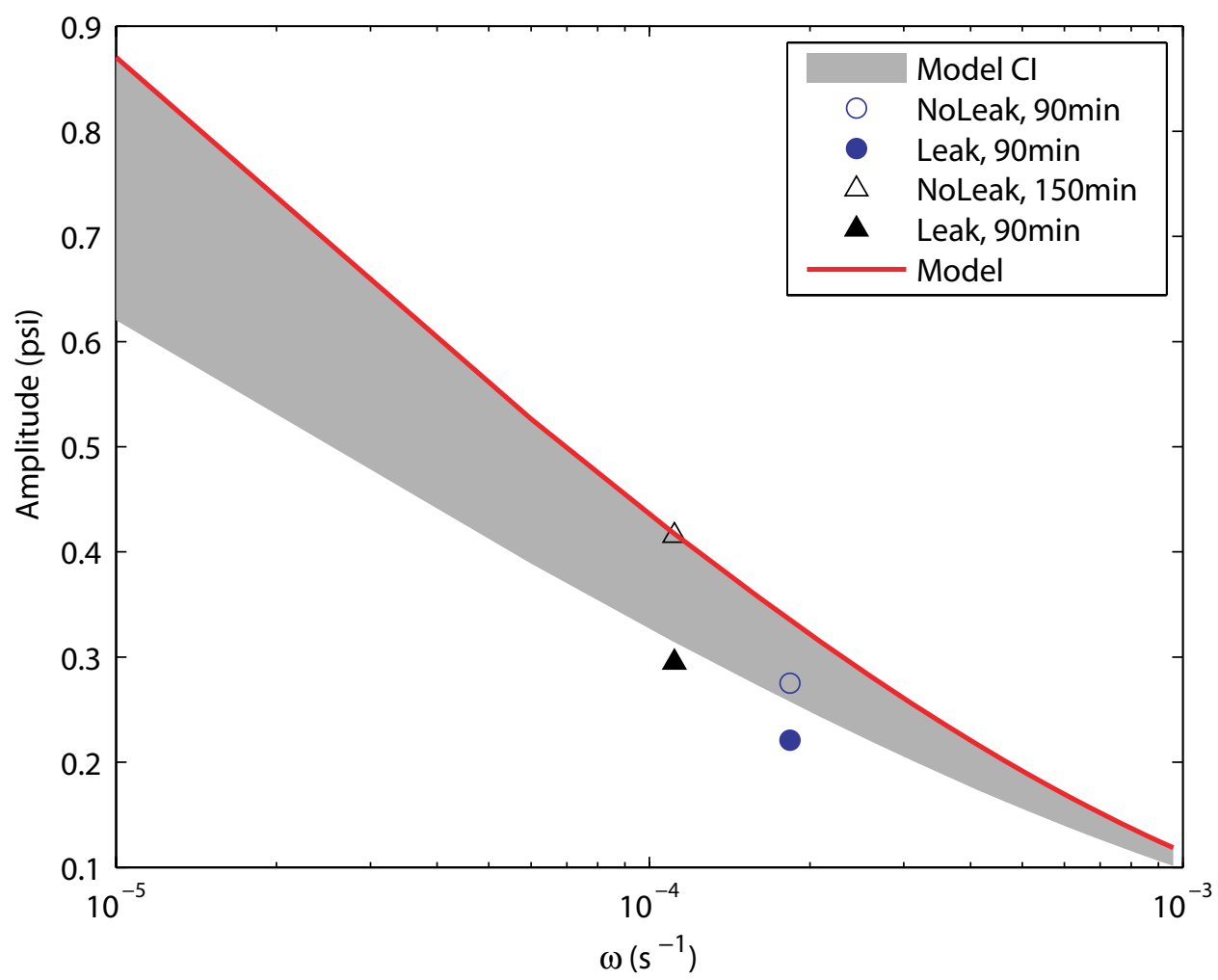

Figure 11: Leak (filled symbols) caused significant deviation in amplitudes of frequency response function as compared to the no-leak case (open symbols). Solid line is calculated using estimated reservoir parameter values and shaded area is formed by using lower $95 \%$ confidence bound. 
(a) $\Delta \mathrm{P} @ \mathrm{~F} 2$

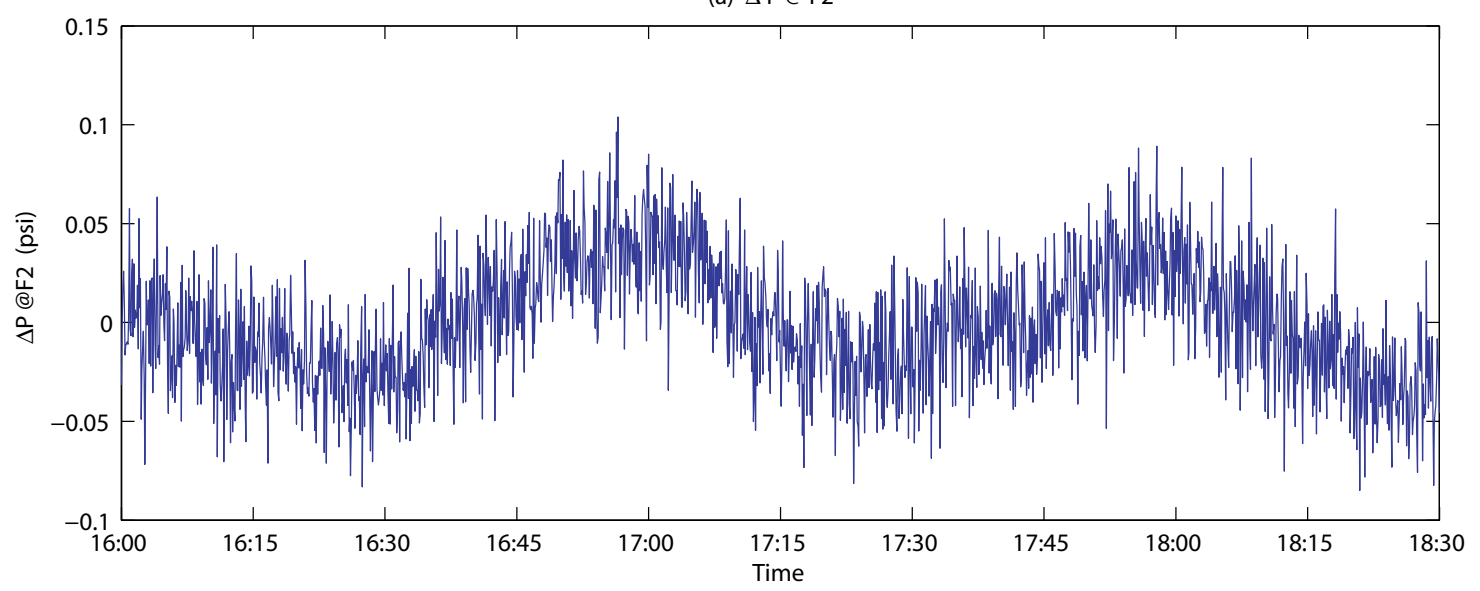

(b) F3 BHP and Leak Rate

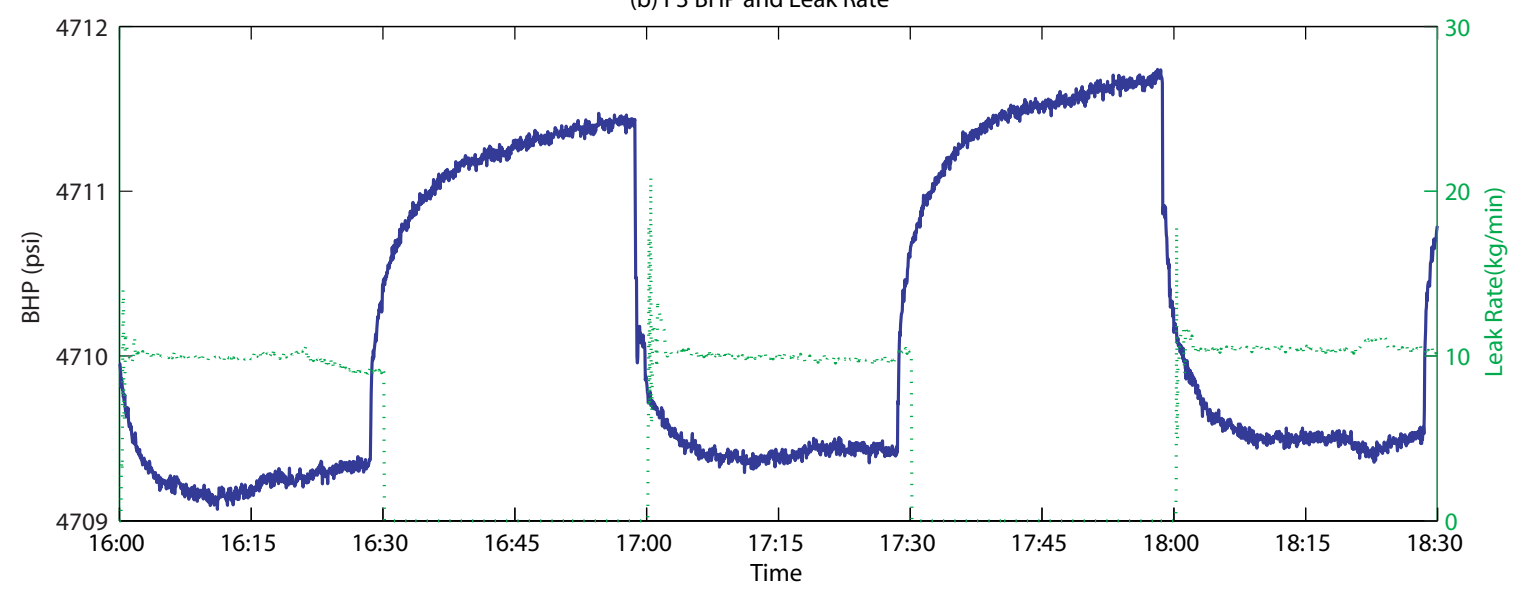

Figure 12: A test used to test sensitivity of F2 to lower venting rates in F3: (a) filtered pressure response, and (b) BHP at F3 (left axis) and leak rate (right axis). A pulse like leak rate was imposed at F3. 